\title{
Oxidative Amide Synthesis and N-Terminal $\alpha$ - Amino Group Ligation of Peptides in Aqueous Medium
}

\author{
Wing-Kei Chan, Chi-Ming Ho, Man-Kin Wong, * and Chi-Ming Che*
}

Department of Chemistry and Open Laboratory of Chemical Biology of the Institute of Molecular Technology for Drug Discovery and Synthesis, The University of Hong Kong, Pokfulam Road, Hong Kong, China

\section{SUPPORTING INFORMATION}


General Experimental Section. Chemicals purchased from commercial sources were used without further purification. Water $\left(\mathrm{ddH}_{2} \mathrm{O}\right)$ used as reaction solvent and in peptide modification was deionized using a NANOpure ${ }^{\mathrm{TM}}$ purification system (Barnstead, USA). Flash column chromatography was performed using silica gel 60 (230-400 mesh ASTM) with ethyl acetate/n-hexane as eluent. GC analysis was conducted by using an HP-5890 series II gas chromatograph equipped with a flame ionization detector and an HP-17 capillary column using $\mathrm{N}_{2}$ as carrier gas. ${ }^{1} \mathrm{H}$ and ${ }^{13} \mathrm{C}-\mathrm{NMR}$ spectra were recorded on a Bruker DPX-300 or DPX-400 spectrometer. Chemical shifts (ppm) were referenced to TMS. IR spectra were recorded on a Bio-Rad FT-IR spectrometer ( $\mathrm{KBr}$ pellet). UV/vis spectra were obtained using an HP 8453 diode array spectrophotometer. Mass spectra were measured using a Finnigan MAT 95 or Finnigan LCQ mass spectrometers.

Mass Spectrometric Analysis for Peptides. For MALDI-TOF MS analysis, all peptide samples were co-crystallized using $\alpha$-cyano-4-hydroxycinnamic acid (Aldrich) solution $\left(10 \mathrm{mg} / \mathrm{mL} \mathrm{CH} \mathrm{CH}_{3} \mathrm{CN} / \mathrm{ddH}_{2} \mathrm{O}\right.$ 1:1 with $0.1 \%$ TFA). MALDI-TOF mass spectra of peptides were recorded in reflectron mode using a Voyager-DE STR ${ }^{\mathrm{TM}}$ system (ABI, USA) equipped with a $\mathrm{N}_{2}$ laser $(337 \mathrm{~nm})$. LC-MS/MS analysis was performed using a hybrid Q-TOF mass spectrometer (QSTAR-XL ${ }^{\mathrm{TM}}$ system, ABI, USA) equipped with an Ionspray source and a Agilent 1100 series cap-LC pump. The reaction mixture chromatography was performed using a Agilent ZORBAX 300SB-C18 $(0.3 \mathrm{~mm} \times 150 \mathrm{~mm})$ reverse phase column with a $\mathrm{CH}_{3} \mathrm{CN} / \mathrm{ddH}_{2} \mathrm{O}$ gradient mobile phase containing $0.1 \%$ formic acid (flow rate: $5 \mu \mathrm{L} / \mathrm{min}$ ).

Procedure for Synthesis of Phenyl Acetamide with " $\mathrm{NH}_{4} \mathrm{HCO}_{3}$ " as Amine Source (eq 1). To a round-bottom flask containing $\left[\mathrm{Mn}\left(2,6-\mathrm{Cl}_{2}-\mathrm{TPP}\right) \mathrm{Cl}\right] \mathbf{1}(0.6 \mu \mathrm{mol})$ and phenylacetylene $2 \mathbf{a}(0.3 \mathrm{mmol})$ in a solution of $\mathrm{CH}_{3} \mathrm{CN}(1.5 \mathrm{~mL})$ and $\mathrm{H}_{2} \mathrm{O}(1 \mathrm{~mL})$ was added a mixture of Oxone $(0.33 \mathrm{mmol})$ and $\mathrm{NH}_{4} \mathrm{HCO}_{3}(1.5 \mathrm{mmol})$. After stirring at room temperature for $1 \mathrm{~h}$, the reaction mixture was quenched by saturated aqueous $\mathrm{Na}_{2} \mathrm{~S}_{2} \mathrm{O}_{3}$ solution $(1 \mathrm{~mL})$, acidified with dilute $\mathrm{HCl}$ solution, and extracted with diethyl ether $(3 \times 20 \mathrm{~mL})$. The combined organic layer was dried over anhydrous $\mathrm{Na}_{2} \mathrm{SO}_{4}$, filtered, and concentrated under reduced pressure. The residue was purified by flash column chromatography $(50 \%$ EtOAc in $n$-hexane) to provide phenyl acetamide ( $80 \%$ yield based on $100 \%$ conversion) as a solid.

Procedure for Gram-Scale Synthesis of Phenyl Acetamide. To a round-bottom flask containing 1 (30 mg, $30 \mu \mathrm{mol}), 2 \mathrm{a}(1 \mathrm{~g}, 9.6 \mathrm{mmol})$ and $\mathrm{NH}_{4} \mathrm{HCO}_{3}(4.66 \mathrm{~g}, 59 \mathrm{mmol})$ in a solution of $\mathrm{CH}_{3} \mathrm{CN}(48$ $\mathrm{mL})$ and $\mathrm{H}_{2} \mathrm{O}(12 \mathrm{~mL})$ was added Oxone $(8.84 \mathrm{~g}, 14.4 \mathrm{mmol})$ in $\mathrm{H}_{2} \mathrm{O}(20 \mathrm{~mL})$ using an addition funnel 
over $30 \mathrm{~min}$. After stirring at room temperature for $2 \mathrm{~h}$, the reaction mixture was quenched by saturated aqueous $\mathrm{Na}_{2} \mathrm{~S}_{2} \mathrm{O}_{3}$ solution $(50 \mathrm{~mL})$, and extracted with ethyl acetate $(4 \times 50 \mathrm{~mL})$. The combined organic layer was dried over anhydrous $\mathrm{Na}_{2} \mathrm{SO}_{4}$, filtered through a short-pad of silica gel, and concentrated under reduced pressure. The residue was purified by re-crystallization $\left(\mathrm{CH}_{2} \mathrm{Cl}_{2} /\right.$ ether) to provide phenyl acetamide (1.1 g, $84 \%$ isolated yield based on $100 \%$ conversion) as a solid. 
Table S1. Optimization of Reaction Conditions for Amide Synthesis

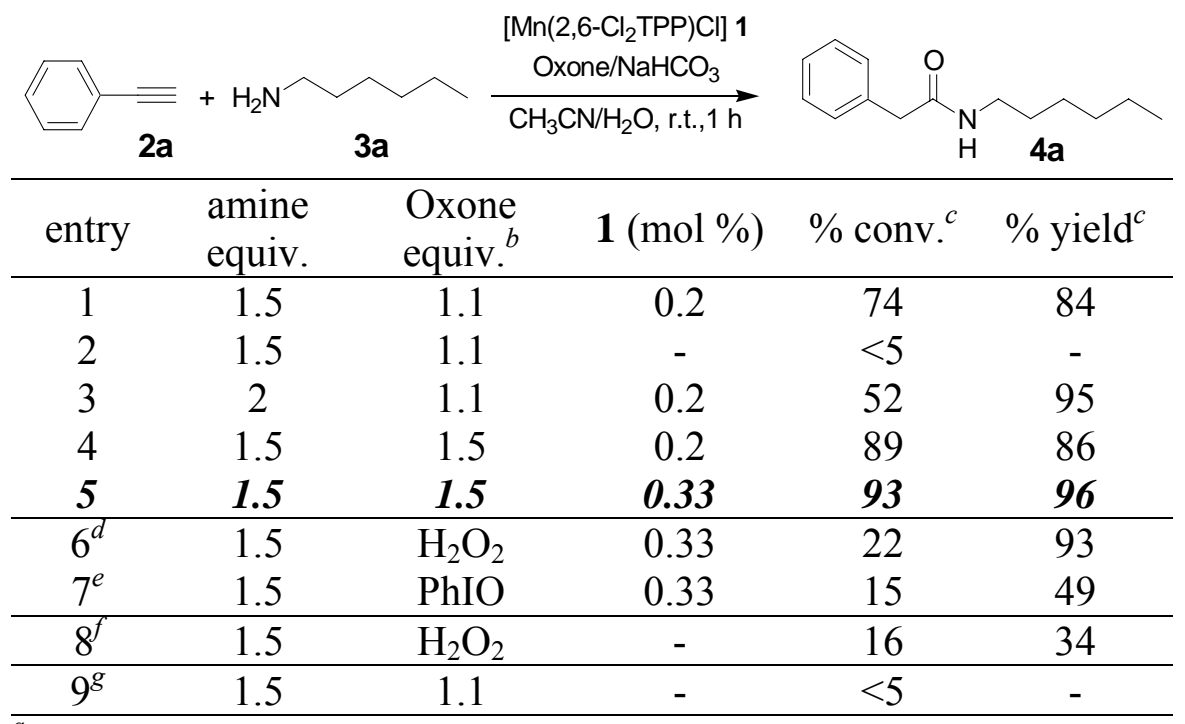

${ }^{a}$ Reaction condition: 2a $(0.3 \mathrm{mmol}), \mathbf{3 a}, \mathbf{1}$, Oxone and $\mathrm{NaHCO}_{3}$ in $\mathrm{CH}_{3} \mathrm{CN}(1.5 \mathrm{~mL})$ and $\mathrm{H}_{2} \mathrm{O}(1 \mathrm{~mL}) ; \mathrm{t}=1$ h; r.t.; unless otherwise stated. ${ }^{b}$ The ratio of Oxone/ $/ \mathrm{NaHCO}_{3}$ was $1: 3.1 .{ }^{c}$ Determined by G.C. with internal standard. ${ }^{d} 30 \% \mathrm{H}_{2} \mathrm{O}_{2}(0.15 \mathrm{~mL})$ was used $(1.5 \mathrm{~h})$. ${ }^{e} \mathrm{PhIO} /$ imidazole in $\mathrm{CH}_{2} \mathrm{Cl}_{2}(1 \mathrm{~h}) .{ }^{f} \mathrm{MnSO}_{4} / \mathrm{NaHCO}_{3}$ in $t-\mathrm{BuOH} / \mathrm{H}_{2} \mathrm{O}$ (4 h). ${ }^{g}$ Methyl pyruvate $(50 \mathrm{mmol} \%$ ) was used instead of $\mathbf{1}$.

General Procedure for Synthesis of Amides using "1 + Oxone” (Table S1, entry 5). To a roundbottom flask containing $1(1 \mu \mathrm{mol})$, $2 \mathbf{a}(0.3 \mathrm{mmol})$, and $\mathbf{3 a}(0.45 \mathrm{mmol})$ in a solution of $\mathrm{CH}_{3} \mathrm{CN}(1.5$ $\mathrm{mL})$ and $\mathrm{H}_{2} \mathrm{O}(1 \mathrm{~mL})$ was added a mixture of Oxone $(0.45 \mathrm{mmol})$ and $\mathrm{NaHCO}_{3}(1.4 \mathrm{mmol})$. After stirring at room temperature for $1 \mathrm{~h}$, the reaction mixture was quenched by saturated aqueous $\mathrm{Na}_{2} \mathrm{~S}_{2} \mathrm{O}_{3}$ solution $(1 \mathrm{~mL})$, acidified with dilute $\mathrm{HCl}$ solution, and extracted with diethyl ether $(3 \times 20 \mathrm{~mL})$. The combined organic layer was added 1,4-dibromobenzene as an internal standard, and the organic compounds were analyzed and quantified by gas chromatography. The yield of $\mathbf{4 a}$ was determined as $96 \%$ based on $93 \%$ alkyne conversion.

Procedure for Synthesis of Amides using “1 $+\mathrm{H}_{2} \mathrm{O}_{2}$ ” (Table S1, entry 6). To a round-bottom flask containing $1(1 \mu \mathrm{mol}), \mathrm{NH}_{4} \mathrm{OAc}(30 \mu \mathrm{mol}), 2 \mathrm{a}(0.3 \mathrm{mmol})$ and $3 \mathbf{a}(0.45 \mathrm{mmol})$ in $\mathrm{CH}_{3} \mathrm{CN}(2.5 \mathrm{~mL})$ was added a premixed solution of $30 \% \mathrm{H}_{2} \mathrm{O}_{2}(0.15 \mathrm{~mL})$ and $\mathrm{H}_{2} \mathrm{O}(1 \mathrm{~mL})$ in three portions for $1 \mathrm{~h}$ at room temperature. After stirring for an additional $0.5 \mathrm{~h}$, the reaction mixture was quenched by saturated aqueous $\mathrm{Na}_{2} \mathrm{~S}_{2} \mathrm{O}_{3}$ solution $(2 \mathrm{~mL})$ and extracted with diethyl ether $(3 \times 20 \mathrm{~mL})$. The combined organic layer was added 1,4-dibromobenzene as an internal standard, and the organic compounds were 
analyzed and quantified by gas chromatography. The yield of $4 a$ was determined as $93 \%$ based on $22 \%$ alkyne conversion.

Procedure for Synthesis of Amides using “1 + PhIO” (Table S1, entry 7). To a dried $\mathrm{CH}_{2} \mathrm{Cl}_{2}$ solution $(3 \mathrm{~mL})$ containing 2a $(0.3 \mathrm{mmol})$ and $3 \mathbf{a}(0.45 \mathrm{mmol})$ was added $\mathbf{1}(1 \mu \mathrm{mol})$, imidazole $(30$ $\mu \mathrm{mol})$ and $\mathrm{PhIO}(0.45 \mathrm{mmol})$. After stirring at room temperature for $1 \mathrm{~h}$, the reaction mixture was added 1,4-dibromobenzene as an internal standard. The organic compounds were analyzed and quantified by gas chromatography. The yield of 4 a was determined as $49 \%$ based on $15 \%$ alkyne conversion.

\section{Preparation of $2 d, 3 d$ and $3 e$}

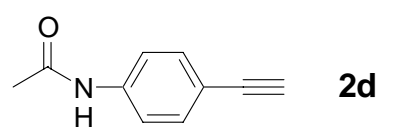

A solution of 2-ethynylaniline $(200 \mathrm{mg}, 1.7 \mathrm{mmol})$ and acetic anhydride $(180 \mu \mathrm{L}, 1.9 \mathrm{mmol})$ in $\mathrm{CH}_{2} \mathrm{Cl}_{2}(5 \mathrm{~mL})$ was stirred at room temperature for $6 \mathrm{~h}$. After evaporation of solvent, the residue was purified by flash column chromatography (40\% EtOAc in $n$-hexane) to afford alkyne $2 \mathbf{d}(253 \mathrm{mg}, 1.6$ mmol, 94\% yield) as a solid. Analytical TLC (silica gel 60) (60\% EtOAc in $n$-hexane), $\mathrm{R}_{f}=0.30 ;{ }^{1} \mathrm{H}$ NMR $\left(300 \mathrm{MHz}, \mathrm{CDCl}_{3}\right) \delta 7.91$ (bs, 1H), 7.50-7.41 (m, 4H), $3.05(\mathrm{~s}, 1 \mathrm{H}), 2.16(\mathrm{~s}, 3 \mathrm{H}) ;{ }^{13} \mathrm{C}$ NMR $\left(100.62 \mathrm{MHz}, \mathrm{CDCl}_{3}\right) \delta 168.7,138.4,132.9,119.4,117.7,83.3,76.8,24.6$; IR (KBr) 3316, 2132, 1667, 1598, $1532 \mathrm{~cm}^{-1}$; EIMS m/z $159\left(\mathrm{M}^{+}\right)$; HRMS (EI) for $\mathrm{C}_{10} \mathrm{H}_{9} \mathrm{NO}$, calcd 159.0684, found 159.0681.

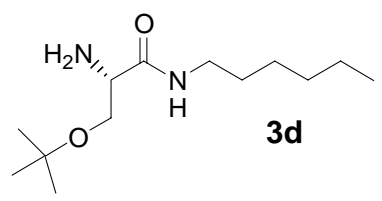

A solution of Fmoc-O-tert-butyl-L-serine (1 g, $2.6 \mathrm{mmol}), N$,N'-diisopropylcarbodiimide (DIC) (470 $\mu \mathrm{L}, 3 \mathrm{mmol})$, and 1-hydroxybenzotriazole (HOBT) $(400 \mathrm{mg}, 3 \mathrm{mmol})$ in $\mathrm{CH}_{2} \mathrm{Cl}_{2}(5 \mathrm{~mL})$ was added hexyl amine ( $400 \mu \mathrm{L}, 3 \mathrm{mmol})$ and stirred at room temperature for $3 \mathrm{~h}$. The reaction mixture was concentrated under reduced pressure. The residue was purified by flash column chromatography $(20 \%$ EtOAc in $n$-hexane) to afford the hexyl amide of Fmoc-O-tert-butyl-L-serine 3d' (1.1 g, $2.5 \mathrm{mmol}$, $96 \%$ yield) as a white solid. 
The Fmoc protecting group of 3d' was deprotected by standard procedure: A solution of 3d' (720 $\mathrm{mg}, 2 \mathrm{mmol})$ in dried THF $(8 \mathrm{~mL})$ was added piperidine $(2 \mathrm{~mL})$ and stirred for $2 \mathrm{~min}$. The reaction mixture was diluted with brine and extracted with ethyl acetate $(3 \times 30 \mathrm{~mL})$. The combined organic layer was dried over anhydrous $\mathrm{Na}_{2} \mathrm{SO}_{4}$, filtered, and concentrated under reduced pressure. The residue was purified by flash column chromatography (EtOAc) to provide 3d (67\% yield) as a yellow oil. ${ }^{1} \mathrm{H}$ NMR (400 MHz, $\left.\mathrm{CDCl}_{3}\right) \delta 7.36(\mathrm{bs}, 1 \mathrm{H}), 3.61$ (dd, $\left.J=5.8,2.8 \mathrm{~Hz} 1 \mathrm{H}\right), 3.49-3.41(\mathrm{~m}, 2 \mathrm{H}), 3.27-3.21$ $(\mathrm{m}, 2 \mathrm{H}), 1.82(\mathrm{bs}, 2 \mathrm{H}), 1.50-1.48(\mathrm{~m}, 2 \mathrm{H}), 1.28-1.26(\mathrm{~m}, 6 \mathrm{H}), 1.19(\mathrm{~s}, 9 \mathrm{H}), 0.89-0.86(\mathrm{~m}, 3 \mathrm{H}) ;{ }^{13} \mathrm{C}$ NMR $\left(100.62 \mathrm{MHz}, \mathrm{CDCl}_{3}\right) \delta 172.8,73.2,63.9,55.3,38.9,31.3,29.5,27.4,26.4,22.4,13.9$; IR $(\mathrm{KBr})$ 3377, 1651, $1364 \mathrm{~cm}^{-1}$; EIMS m/z $244\left(\mathrm{M}^{+}\right)$; HRMS (EI) for $\mathrm{C}_{13} \mathrm{H}_{28} \mathrm{~N}_{2} \mathrm{O}_{2}$, calcd 244.2150, found 244.2142 .

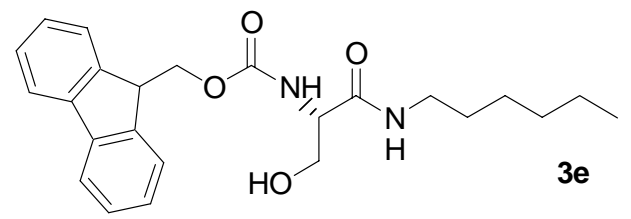

A solution of 3d' (390 mg, $0.8 \mathrm{mmol})$ in dried $\mathrm{CH}_{2} \mathrm{Cl}_{2}(5 \mathrm{~mL})$ was added trifluoroacetic acid (1 $\mathrm{mL}$ ) and stirred for $5 \mathrm{~min}$. The reaction mixture was diluted with brine and extracted with ethyl acetate $(3 \times 30 \mathrm{~mL})$. The combined organic layer was dried over anhydrous $\mathrm{Na}_{2} \mathrm{SO}_{4}$, filtered, and concentrated under reduced pressure. The residue was purified by flash column chromatography $(50 \%$ EtOAc in $n$ hexane) to provide $3 \mathbf{e}(200 \mathrm{mg}, 0.49 \mathrm{mmol}, 61 \%$ yield) as a white solid. Analytical TLC (silica gel 60) (80\% EtOAc in $n$-hexane), $\mathrm{R}_{f}=0.33 ;{ }^{1} \mathrm{H}$ NMR $\left(300 \mathrm{MHz}, \mathrm{CDCl}_{3}\right) \delta 7.78-7.76(\mathrm{~m}, 2 \mathrm{H}), 7.59-7.57(\mathrm{~m}$, 2H), 7.43-7.26 (m, 4H), $6.53(\mathrm{bs}, 1 \mathrm{H}), 5.86(\mathrm{bs}, 1 \mathrm{H}), 4.43$ (bd, $J=6.51 \mathrm{~Hz}, 2 \mathrm{H}), 4.24-4.10(\mathrm{~m}, 3 \mathrm{H})$, 3.67-3.64 (m, 1H), 3.24-3.11 (m, 2H), $1.66(\mathrm{bs}, 1 \mathrm{H}), 1.48-1.39$ (m, 2H), 1.26-1.21 (m, 6H), 0.88-0.84 $(\mathrm{m}, 3 \mathrm{H}) ;{ }^{13} \mathrm{C}$ NMR $\left(75.48 \mathrm{MHz}, \mathrm{CDCl}_{3}\right) \delta 171.3,157.3,144.1,141.8,127.8,127.1,125.0,120.5,67.8$, 63.4, 56.0, 47.6, 40.2, 31.9, 29.8, 27.0, 23.0, 14.0; IR (KBr) 3400, $1649 \mathrm{~cm}^{-1}$; EIMS m/z $410\left(\mathrm{M}^{+}\right)$; HRMS (EI) for $\mathrm{C}_{24} \mathrm{H}_{30} \mathrm{~N}_{2} \mathrm{O}_{4}$, calcd 410.2206, found 410.2215.

\section{Characterization Data of Amides 4a-4j}

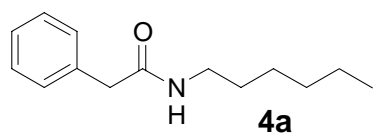

Analytical TLC (silica gel 60) (60\% EtOAc in $n$-hexane), $\mathrm{R}_{f}=0.41 ;{ }^{1} \mathrm{H}$ NMR $(300 \mathrm{MHz}$, $\left.\mathrm{CDCl}_{3}\right) \delta$ 7.36-7.26 (m, 5H), 5.72 (bs, $\left.1 \mathrm{H}\right), 3.54$ (s, 2H), 3.21-3.15 (m, 2H), 1.43-1.41 (m, 2H), 1.25$1.20(\mathrm{~m}, 6 \mathrm{H}), 0.87-0.83(\mathrm{~m}, 3 \mathrm{H}) ;{ }^{13} \mathrm{C} \mathrm{NMR}\left(75.48 \mathrm{MHz}, \mathrm{CDCl}_{3}\right) \delta 170.9,135.2,129.6,128.9,127.2$, 
43.8, 39.7, 31.4, 29.4, 26.4, 22.5, 13.9; IR (KBr) 3412, $1629 \mathrm{~cm}^{-1}$; EIMS $m / z 219\left(\mathrm{M}^{+}\right)$; HRMS (EI) for $\mathrm{C}_{14} \mathrm{H}_{21} \mathrm{NO}$, calcd 219.1623, found 219.1624.

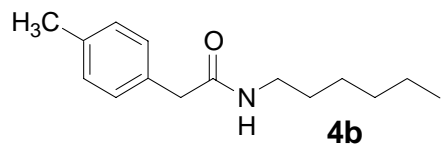

Analytical TLC (silica gel 60) (50\% EtOAc in $n$-hexane), $\mathrm{R}_{f}=0.53 ;{ }^{1} \mathrm{H}$ NMR (300 MHz, $\left.\mathrm{CDCl}_{3}\right) \delta 7.17-7.11(\mathrm{~m}, 4 \mathrm{H}), 5.47(\mathrm{bs}, 1 \mathrm{H}), 3.52(\mathrm{~s}, 2 \mathrm{H}), 3.21-3.14(\mathrm{~m}, 2 \mathrm{H}), 2.34(\mathrm{~s}, 3 \mathrm{H}), 1.43-1.29(\mathrm{~m}$, 2H), 1.27-1.18 (m, 6H), 0.87-0.83 (m, 3H); ${ }^{13} \mathrm{C}$ NMR (75.48 MHz, $\left.\mathrm{CDCl}_{3}\right) \delta$ 171.1, 136.9, 131.9, 129.6, 129.3, 43.4, 39.6, 31.3, 29.3, 26.3, 22.4, 21.0, 13.9; IR (KBr) 3478, $1645 \mathrm{~cm}^{-1}$; EIMS m/z 233 $\left(\mathrm{M}^{+}\right)$; HRMS (EI) for $\mathrm{C}_{15} \mathrm{H}_{23} \mathrm{NO}$, calcd 233.1780, found 233.1780.

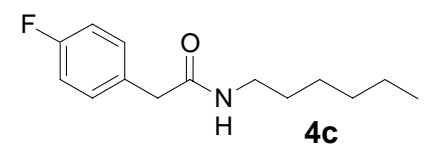

Analytical TLC (silica gel 60) (60\% EtOAc in $n$-hexane), $\mathrm{R}_{f}=0.41 ;{ }^{1} \mathrm{H}$ NMR $(300 \mathrm{MHz}$, $\left.\mathrm{CDCl}_{3}\right) \delta$ 7.26-7.19 (m, 2H), 7.04-6.98 (m, 2H), 5.60 (bs, 1H), 3.49 (s, 2H), 3.21-3.14 (m, 2H), 1.43$1.36(\mathrm{~m}, 2 \mathrm{H}), 1.28-1.21(\mathrm{~m}, 6 \mathrm{H}), 0.86-0.82(\mathrm{~m}, 3 \mathrm{H}) ;{ }^{13} \mathrm{C} \mathrm{NMR}\left(75.48 \mathrm{MHz}, \mathrm{CDCl}_{3}\right) \delta 170.6,163.6$, $160.4,130.9,130.8,115.8,115.5,42.8,39.7,31.3,29.3,26.4,22.4,13.9$; IR (KBr) $3468,1629 \mathrm{~cm}^{-1}$; EIMS $m / z 237\left(\mathrm{M}^{+}\right)$; HRMS (EI) for $\mathrm{C}_{14} \mathrm{H}_{20} \mathrm{NOF}$, calcd 237.1529, found 237.1528.

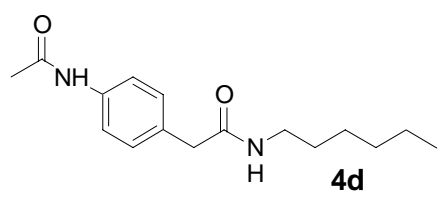

Analytical TLC (silica gel 60) (100\% EtOAc), $\mathrm{R}_{f}=0.26 ;{ }^{1} \mathrm{H}$ NMR $\left(300 \mathrm{MHz}, \mathrm{CDCl}_{3}\right) \delta 7.56$ (bs, 1H), 7.46 (d, J=7.9 Hz, 2H), 7.18 (d, J=7.9 Hz, 2H), 5.46 (bs, 1H), 3.51 (s, 2H), 3.22-3.16 (m, 2H), $2.17(\mathrm{~s}, 3 \mathrm{H}), 1.43-1.39(\mathrm{~m}, 2 \mathrm{H}), 1.26-1.23(\mathrm{~m}, 6 \mathrm{H}), 0.88-0.83(\mathrm{~m}, 3 \mathrm{H}) ;{ }^{13} \mathrm{C}$ NMR $(75.48 \mathrm{MHz}$, $\left.\mathrm{CDCl}_{3}\right) \delta 171.0168 .8,137.2,130.6,129.9,120.5,43.2,39.8,31.3,29.4,26.4,24.4,22.5,13.9$; IR (KBr) 3429, $1636 \mathrm{~cm}^{-1}$; EIMS m/z $276\left(\mathrm{M}^{+}\right)$; HRMS (EI) for $\mathrm{C}_{16} \mathrm{H}_{24} \mathrm{~N}_{2} \mathrm{O}_{2}$, calcd 276.1838, found 276.1839 . 


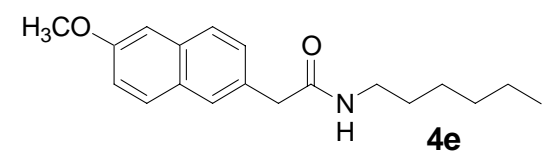

Analytical TLC (silica gel 60) (50\% EtOAc in $n$-hexane), $\mathrm{R}_{f}=0.46 ;{ }^{1} \mathrm{H}$ NMR $(400 \mathrm{MHz}$, $\left.\mathrm{CDCl}_{3}\right) \delta$ 7.74-7.69 (m, 2H), $7.62(\mathrm{~s}, 1 \mathrm{H})$, 7.33-7.31 (m, 2H), 7.18-7.13 (m, 2H), 5.45 (bs, 1H). 3.92 (s. $3 \mathrm{H}), 3.74(\mathrm{~s}, 2 \mathrm{H}), 3.21-3.16(\mathrm{~m}, 2 \mathrm{H}), 1.43-1.36(\mathrm{~m}, 2 \mathrm{H}), 1.25-1.20(\mathrm{~m}, 6 \mathrm{H}), 0.88-0.81(\mathrm{~m}, 3 \mathrm{H}) ;{ }^{13} \mathrm{C}$ NMR $\left(75.48 \mathrm{MHz}, \mathrm{CDCl}_{3}\right) \delta 171.0,157.8,133.6,130.1,129.1,128.1,127.8,127.6,119.2,105.66$, 55.3, 43.8, 39.7, 31.3, 29.4, 26.4, 22.4, 13.9; IR (KBr) 3427, $1639 \mathrm{~cm}^{-1}$; EIMS $m / z 299\left(\mathrm{M}^{+}\right)$; HRMS (EI) for $\mathrm{C}_{19} \mathrm{H}_{25} \mathrm{NO}_{2}$, calcd 299.1885, found 299.1894 .

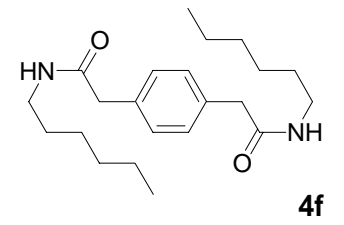

${ }^{1} \mathrm{H}$ NMR (300 MHz, $\left.\mathrm{CDCl}_{3}\right) \delta 7.24(\mathrm{~s}, 4 \mathrm{H}), 5.45(\mathrm{bs}, 2 \mathrm{H}), 3.70(\mathrm{~s}, 4 \mathrm{H}), 3.22-3.18(\mathrm{~m}, 4 \mathrm{H})$, 1.44-1.41 (m, 4H), 1.26-1.23 (m, 12H), 0.88-0.84 (m, 6H); ${ }^{13} \mathrm{C}$ NMR (100.62 MHz, $\left.\mathrm{CDCl}_{3}\right) \delta 170.8$, 134.2, 130.1, 43.5, 39.9, 31.5, 29.5, 26.6, 22.6, 14.1; IR (KBr) 3401, $1632 \mathrm{~cm}^{-1}$; EIMS $m / z 360\left(\mathrm{M}^{+}\right)$; HRMS (EI) for $\mathrm{C}_{22} \mathrm{H}_{36} \mathrm{~N}_{2} \mathrm{O}_{2}$, calcd 360.2777 , found 360.2775 .

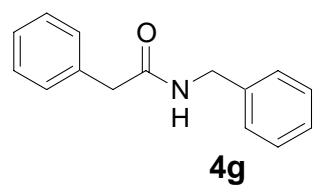

Analytical TLC (silica gel 60) (50\% EtOAc in $n$-hexane) $\mathrm{R}_{f}=0.39 ;{ }^{1} \mathrm{H}$ NMR (400 MHz, $\mathrm{CDCl}_{3}$ )

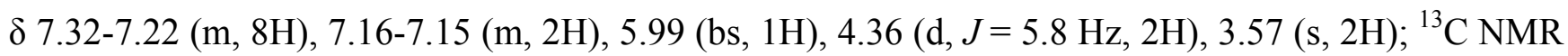
$\left(100.62 \mathrm{MHz}, \mathrm{CDCl}_{3}\right) \delta 170.9,138.1,134.8,129.3,128.9,128.5,127.4,127.3,127.2,43.6,43.4$; IR (KBr) 3429, $1641 \mathrm{~cm}^{-1}$; EIMS $m / z 225\left(\mathrm{M}^{+}\right)$; HRMS (EI) for $\mathrm{C}_{15} \mathrm{H}_{15} \mathrm{NO}$, calcd 225.1154, found 225.1156 .

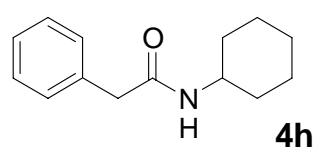

Analytical TLC (silica gel 60) (50\% EtOAc in $n$-hexane), $\mathrm{R}_{f}=0.39 ;{ }^{1} \mathrm{H}$ NMR $(400 \mathrm{MHz}$, $\left.\mathrm{CDCl}_{3}\right) \delta$ 7.26-7.24 (m, 5H), 5.43 (bs, $\left.1 \mathrm{H}\right), 3.78-3.71(\mathrm{~m}, 1 \mathrm{H}), 3.53(\mathrm{~s}, 2 \mathrm{H}), 1.85-1.81(\mathrm{~m}, 2 \mathrm{H}), 1.63-$ $1.58(\mathrm{~m}, 3 \mathrm{H}), 1.34-1.30(\mathrm{~m}, 2), 1.04-1.00(\mathrm{~m}, 3 \mathrm{H}) ;{ }^{13} \mathrm{C} \mathrm{NMR}\left(100.62 \mathrm{MHz}, \mathrm{CDCl}_{3}\right) \delta 170.1,135.2$, 
129.3, 128.9, 127.2, 48.2, 44.0, 32.9, 25.5, 24.7; IR (KBr) 3435, $1636 \mathrm{~cm}^{-1}$; EIMS m/z $217\left(\mathrm{M}^{+}\right)$; HRMS (EI) for $\mathrm{C}_{14} \mathrm{H}_{19} \mathrm{NO}$, calcd 217.1467, found 217.1459.

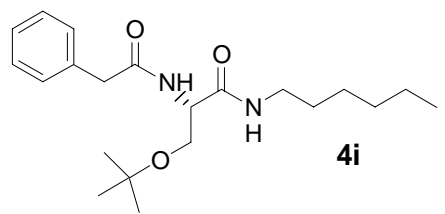

Analytical TLC (silica gel 60) (50\% EtOAc in $n$-hexane), $\mathrm{R}_{f}=0.26 ;{ }^{1} \mathrm{H}$ NMR $(300 \mathrm{MHz}$, $\left.\mathrm{CDCl}_{3}\right) \delta 7.37-7.26(\mathrm{~m}, 5 \mathrm{H}), 6.58(\mathrm{bs}, 1 \mathrm{H}), 6.50(\mathrm{bd}, J=6.1 \mathrm{~Hz}, 1 \mathrm{H}), 4.36-4.33(\mathrm{~m}, 1 \mathrm{H}), 3.76(\mathrm{dd}, J=$ 8.6, 4.2 Hz, 1H), 3.60 (s, 2H), 3.26-3.16 (m, 3H), 1.47-1.43 (m, 2H), 1.30-1.27 (m, 6H), 1.14 (s, 9H), 0.90-0.86 (m, 3H); ${ }^{13} \mathrm{C}$ NMR (75.48 MHz, $\left.\mathrm{CDCl}_{3}\right) \delta 171.0,170.0,134.6,129.3,128.9,127.3,74.0$, 61.1, 52.9, 43.6, 39.4, 31.4, 29.3, 27.3, 26.4, 22.5, 14.0; IR (KBr) 3429, 1638, $1362 \mathrm{~cm}^{-1}$; EIMS m/z $362\left(\mathrm{M}^{+}\right)$; HRMS (EI) for $\mathrm{C}_{21} \mathrm{H}_{34} \mathrm{~N}_{2} \mathrm{O}_{3}$, calcd 362.2570, found 362.2579.

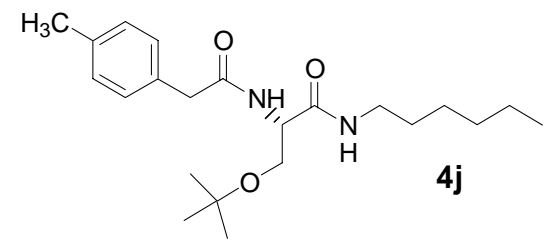

Analytical TLC (silica gel 60) (50\% EtOAc in $n$-hexane), $\mathrm{R}_{f}=0.37 ;{ }^{1} \mathrm{H}$ NMR (300 MHz, $\left.\mathrm{CDCl}_{3}\right) \delta 7.16(\mathrm{~s}, 4 \mathrm{H}), 6.54(\mathrm{bs}, 1 \mathrm{H}), 6.45(\mathrm{bd}, J=6.1 \mathrm{~Hz}, 1 \mathrm{H}), 4.36-4.30(\mathrm{~m}, 1 \mathrm{H}), 3.45(\mathrm{dd}, J=8.6$, $4.1 \mathrm{~Hz}, 1 \mathrm{H}), 3.56$ (s, 2H), 3.24-3.17 (m, 3H), 2.33 (s, 3H), 1.47-1.40 (m, 2H), 1.30-1.28 (m, 6H), 1.13 (s, 9H), 0.90-0.86 (m, 3H); ${ }^{13} \mathrm{C}$ NMR (75.48 MHz, $\left.\mathrm{CDCl}_{3}\right) \delta 173.0,170.0,136.9,131.5,129.6,129.1$, 74.0, 61.1, 52.8, 43.2, 39.4, 31.4, 29.3, 27.3, 26.4, 22.5, 21.0, 14.0; IR (KBr) 3435, $1638 \mathrm{~cm}^{-1}$; EIMS $m / z 319\left(\mathrm{M}^{+}-\mathrm{C}_{4} \mathrm{H}_{9}\right)$; HRMS (EI) for $\mathrm{C}_{18} \mathrm{H}_{27} \mathrm{~N}_{2} \mathrm{O}_{3}$, calcd 319.2022, found 319.2027.

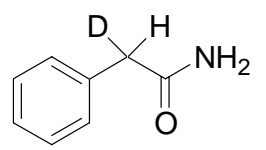

Analytical TLC (silica gel 60) (100\% EtOAc), $\mathrm{R}_{f}=0.24 ;{ }^{1} \mathrm{H}$ NMR $\left(300 \mathrm{MHz}, \mathrm{CDCl}_{3}\right) \delta 7.38$ 7.25 (m, 5H), 5.60 (bs, 1H), $5.40(\mathrm{bs}, 1 \mathrm{H}), 3.58(\mathrm{~s}, 1 \mathrm{H}) ;{ }^{13} \mathrm{C} \mathrm{NMR}\left(75.48 \mathrm{MHz}, \mathrm{CDCl}_{3}\right) \delta 173.9,134.7$, 129.3, 129.0, 127.4, 43.3, 43.0, 42.7; EIMS m/z $136\left(\mathrm{M}^{+}\right)$; HRMS (EI) for $\mathrm{C}_{8} \mathrm{H}_{8} \mathrm{DNO}$, calcd 136.0745, found 136.0746 . 


\section{Literature References of Known Compounds}

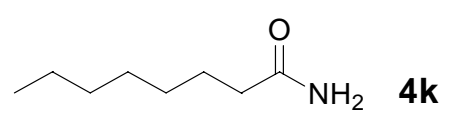

Lazbin, I. M.; Koser, G. F. J. Org. Chem. 1986, 51, 2669.

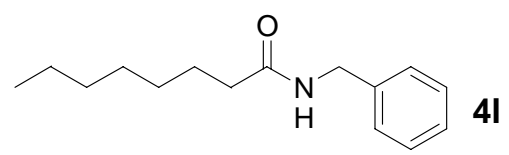

Grieco, P. A.; Clark, D. S.; Withers, G. P. J. Org. Chem. 1979, 44, 2945.

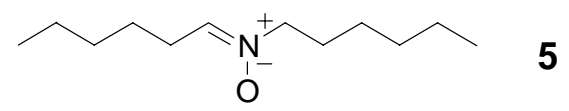

Yamazaki, S. Bull. Chem. Soc. Jpn. 1997, 70, 877.

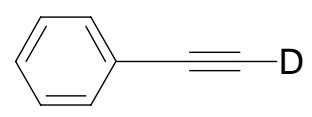

Zeller, K.-P.; Kowallik, M.; Haiss, P. Org. Biomol. Chem. 2005, 3, 231.

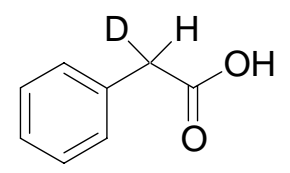

Zeller, K.-P.; Kowallik, M.; Haiss, P. Org. Biomol. Chem. 2005, 3, 231.

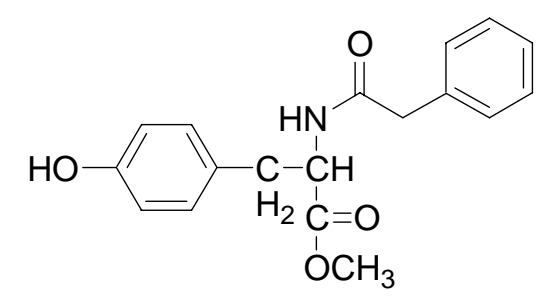

Carboni, C.; Quaedflieg, P. J. L. M.; Broxterman, Q. B.; Linad, P.; Gardossi, L. Tetrahedron Lett. 2004, 45,9649 .

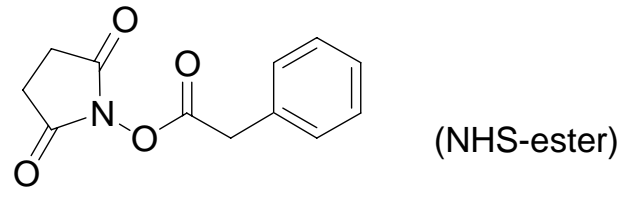

Stembera, K.; Buchynskyy, A.; Vogel, S.; Knoll, D.; Osman, A. A.; Ayala, J. A.; Welzel, P. Chembiochem 2002, 3, 332. 
Coupling of Aniline with 2a using “1 + Oxone”. To a round-bottom flask containing 1 (1 $\mu$ mol), 2a $(0.3 \mathrm{mmol})$, and aniline $(0.45 \mathrm{mmol})$ in a solution of $\mathrm{CH}_{3} \mathrm{CN}(1.5 \mathrm{~mL})$ and $\mathrm{H}_{2} \mathrm{O}(1 \mathrm{~mL})$ was added a mixture of Oxone $(0.45 \mathrm{mmol})$ and $\mathrm{NaHCO}_{3}(1.4 \mathrm{mmol})$. After stirring at room temperature for $1 \mathrm{~h}$, the reaction mixture was quenched by addition of saturated aqueous $\mathrm{Na}_{2} \mathrm{~S}_{2} \mathrm{O}_{3}$ solution $(1 \mathrm{~mL})$, acidified with dilute $\mathrm{HCl}$ solution, and extracted with diethyl ether $(3 \times 20 \mathrm{~mL})$. The combined organic layer was added 1,4-dibromobenzene as an internal standard, and the organic compounds were analyzed and quantified by GC-MS (Agilent 6890N and 5973N) using an Agilent HP-5 column (30 m $\times 250 \mu \mathrm{m} \times$ $0.25 \mu \mathrm{m})$. The yield of azoxybenzene was determined to be $83 \%$ based on $91 \%$ aniline conversion, and $93 \%$ of 2 a was recovered. No amide product was observed.

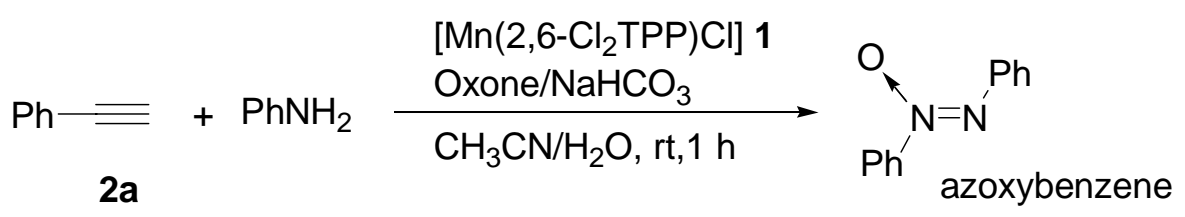




\section{A Scrambling Oxidative Amide Synthesis Experiment using a 1 : 1 Ratio of Deutero-1-}

phenylacetylene and $\mathbf{2 b}$ Catalyzed by “ 1 + Oxone”. To a round-bottom flask containing 1 (1 $\mu$ mol), deutero-1-phenylacetylene $(0.15 \mathrm{mmol}), 2 \mathbf{b}(4-\mathrm{MePhC} \equiv \mathrm{CH}, 0.15 \mathrm{mmol})$ in a solution of $\mathrm{CH}_{3} \mathrm{CN}(1.5$ $\mathrm{mL})$ and $\mathrm{H}_{2} \mathrm{O}(1 \mathrm{~mL})$ was added a mixture of Oxone $(0.45 \mathrm{mmol})$ and $\mathrm{NH}_{4} \mathrm{HCO}_{4}(1.5 \mathrm{mmol})$. After stirring at room temperature for $1 \mathrm{~h}$, the reaction mixture was quenched by addition of saturated aqueous $\mathrm{Na}_{2} \mathrm{~S}_{2} \mathrm{O}_{3}$ solution $(1 \mathrm{~mL})$, acidified with dilute $\mathrm{HCl}$ solution, and extracted with diethyl ether $(3 \times 20 \mathrm{~mL})$. The combined organic layer was added 1,4-dibromobenzene as an internal standard, and the organic compounds were analyzed and quantified by GC-MS (Agilent $6890 \mathrm{~N}$ and 5973N) using a HP-5 column. The yields of $\mathrm{PhCHDCONH}_{2}(\mathrm{t}=11.7 \mathrm{~min})$ and $4-\mathrm{MePhCH}_{2} \mathrm{CONH}_{2}(\mathrm{t}=12.3 \mathrm{~min})$ were determined as 92\% and 94\%, respectively, based on complete substrate conversion (Figure A). No cross-over of deuterium in the amide products was observed by MS (Figures B and C).
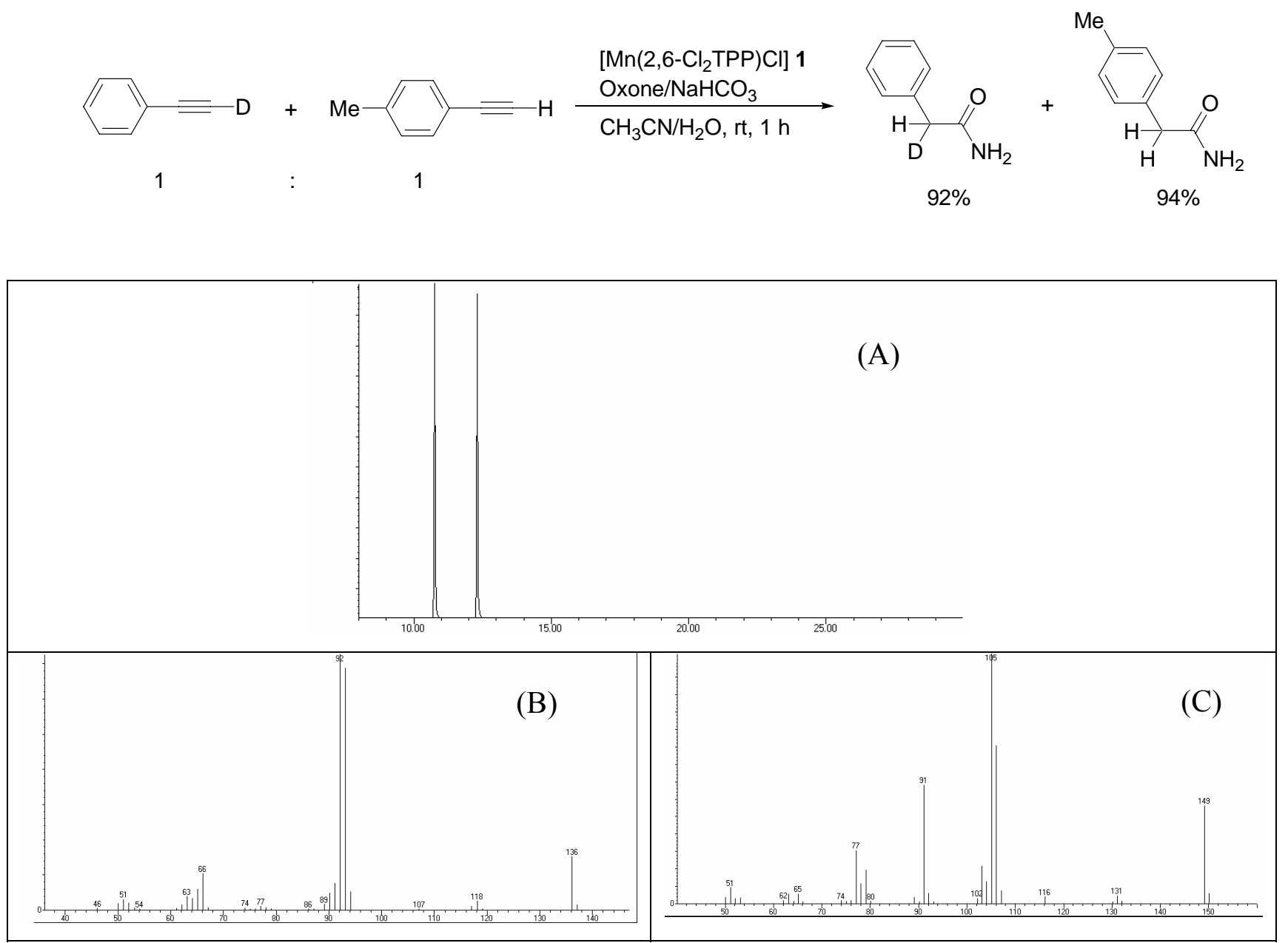

Figure (A) GC-MS chromatograph of the scrambling experiment. (B) MS spectrum of $\mathrm{PhCHDCONH}_{2}$ $(\mathrm{t}=11.7 \mathrm{~min})\left(\mathrm{M}^{+}=136\right)$. (C) MS spectrum of $4-\mathrm{MePhCH}_{2} \mathrm{CONH}_{2}(\mathrm{t}=12.3 \mathrm{~min})\left(\mathrm{M}^{+}=149\right)$. 
Solid-Phase Synthesis of Peptides. Peptides were synthesized according to standard solid phase Fmoc-peptide synthesis procedure using Wang resin as solid support and purified by preparative reversed-phase HPLC equipped with a $\mathrm{C}_{18}$ column using $\mathrm{CH}_{3} \mathrm{CN} / \mathrm{H}_{2} \mathrm{O} / \mathrm{TFA}$ as the solvent system. The amino acid sequence of peptides was confirmed by tandem mass spectrometric (MS/MS) analysis.

Peptides synthesized:

YTSSSKNVVR

TYGPVFMSL

STSSSCNLSK

SSCSSCPLSK

Peptides obtained from commercial sources:

GEQRKDVYVQLYL

HDMNKVLDL 


\section{General Procedure for N-terminal Modification of Peptides with $\mathrm{H}_{2} \mathrm{O}_{2}$}

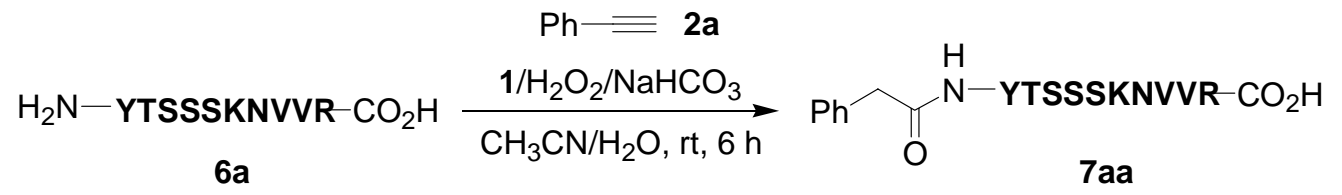

In a $1.0 \mathrm{~mL}$ eppendorf tube, $50 \mu \mathrm{L}$ of $\mathbf{6 a}\left(1 \mathrm{mg} / \mathrm{mL}\right.$ in $\left.\mathrm{H}_{2} \mathrm{O}\right), 5 \mu \mathrm{L}$ of $\mathbf{2 a}\left(5 \mathrm{mg} / \mathrm{mL}\right.$ in $\left.\mathrm{CH}_{3} \mathrm{CN}\right), 5 \mu \mathrm{L}$ of $1\left(2 \mathrm{mg} / \mathrm{mL}\right.$ in $\left.\mathrm{CH}_{3} \mathrm{CN}\right), 0.6 \mu \mathrm{L}$ of $\mathrm{H}_{2} \mathrm{O}_{2}(30 \% \mathrm{v} / \mathrm{v}), 10 \mu \mathrm{L}$ of $\mathrm{NaHCO}_{3}\left(4 \mathrm{mg} / \mathrm{mL}\right.$ in $\left.\mathrm{H}_{2} \mathrm{O}, \mathrm{pH} 8.3\right)$ and $430 \mu \mathrm{L}$ of $\mathrm{CH}_{3} \mathrm{CN} / \mathrm{H}_{2} \mathrm{O}(3: 2)$ were mixed. The reaction mixture was incubated at $25{ }^{\circ} \mathrm{C}$ for $6 \mathrm{~h}$. The Nterminal modified peptide 7aa was characterized by MALDI-TOF and LC-MS/MS analyses.

Apart from the $\alpha$-amino group, the phenol group of terminal tyrosine of peptide $\mathbf{6 a}$ might also act as a nucleophile to couple with 2a. As the exact molecular structure of the terminal tyrosine of 7aa could not be determined by mass spectrometry, we conducted a model study by using tyrosine- $\mathrm{OCH}_{3}$ to mimic the structure of 7aa (eq. S1). The corresponding amide product was obtained as a sole product in $90 \%$ isolated yield. (With $\mathrm{H}_{2} \mathrm{O}_{2}$ as oxidant and $5 \%$ of $\mathbf{1}$, the corresponding amide was obtained as a sole product in $60 \%$ isolated yield). No O-acylated product was detected. Thus, this model reaction provided an experimental evidence to support the attachment of $2 \mathbf{a}$ to the $\alpha$-amino group of the $\mathrm{N}$ terminal tyrosine of peptide 7aa.

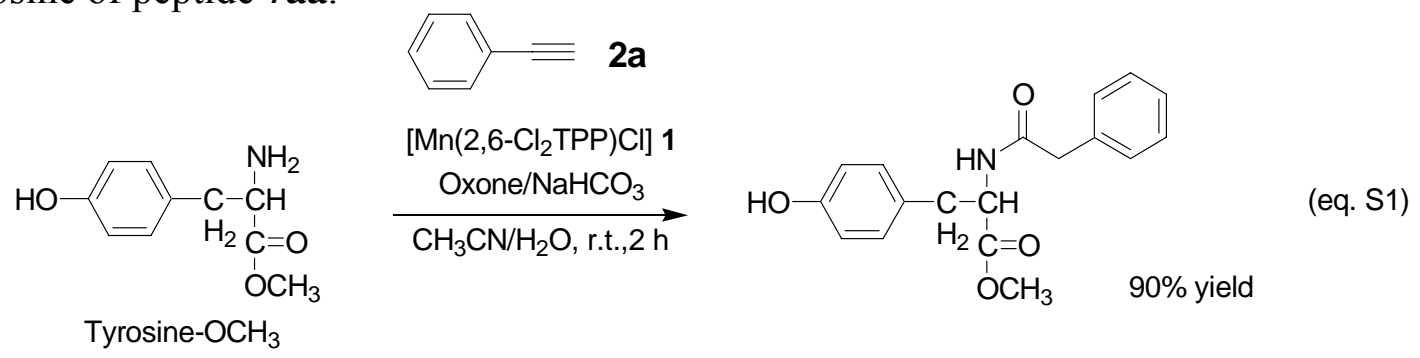

Procedure: To a round-bottom flask containing 1 ( $2 \mu \mathrm{mol})$, tyrosine- $\mathrm{OCH}_{3}(0.2 \mathrm{mmol})$, and 2a $(0.2 \mathrm{mmol})$ in a solution of $\mathrm{CH}_{3} \mathrm{CN}(2.1 \mathrm{~mL})$ and $\mathrm{H}_{2} \mathrm{O}(1.4 \mathrm{~mL})$ was added a mixture of Oxone $(0.3$ mmol) and $\mathrm{NaHCO}_{3}(0.93 \mathrm{mmol})$. After stirring at room temperature for $2 \mathrm{~h}$, the reaction mixture was quenched by saturated aqueous $\mathrm{Na}_{2} \mathrm{~S}_{2} \mathrm{O}_{3}$ solution $(1 \mathrm{~mL})$, acidified with dilute $\mathrm{HCl}$ solution, and extracted with diethyl ether $(3 \times 20 \mathrm{~mL})$. The residue was purified by flash column chromatography (20\% EtOAc in $n$-hexane) to the corresponding amide (57 mg, $0.18 \mathrm{mmol}, 90 \%$ yield) [Tetrahedron Lett. 2004, 45, 9649]. 


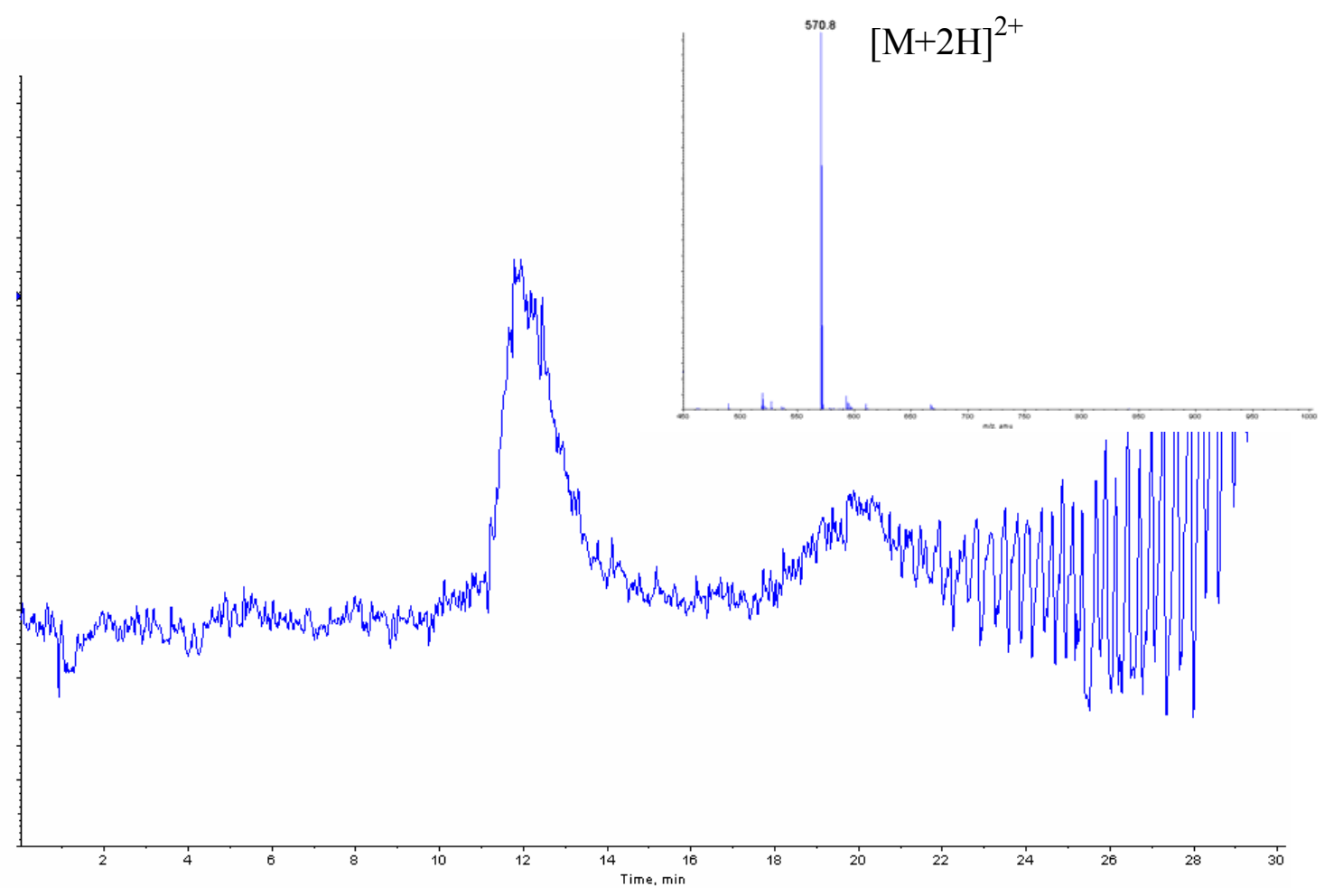

Figure S1. The base peak ion chromatogram of $6 \mathbf{6}$ (doubly charge ion $\mathrm{m} / \mathrm{z}=570.8$ ) and the full mass spectrum at retention time of $12 \mathrm{~min}$ (inset).

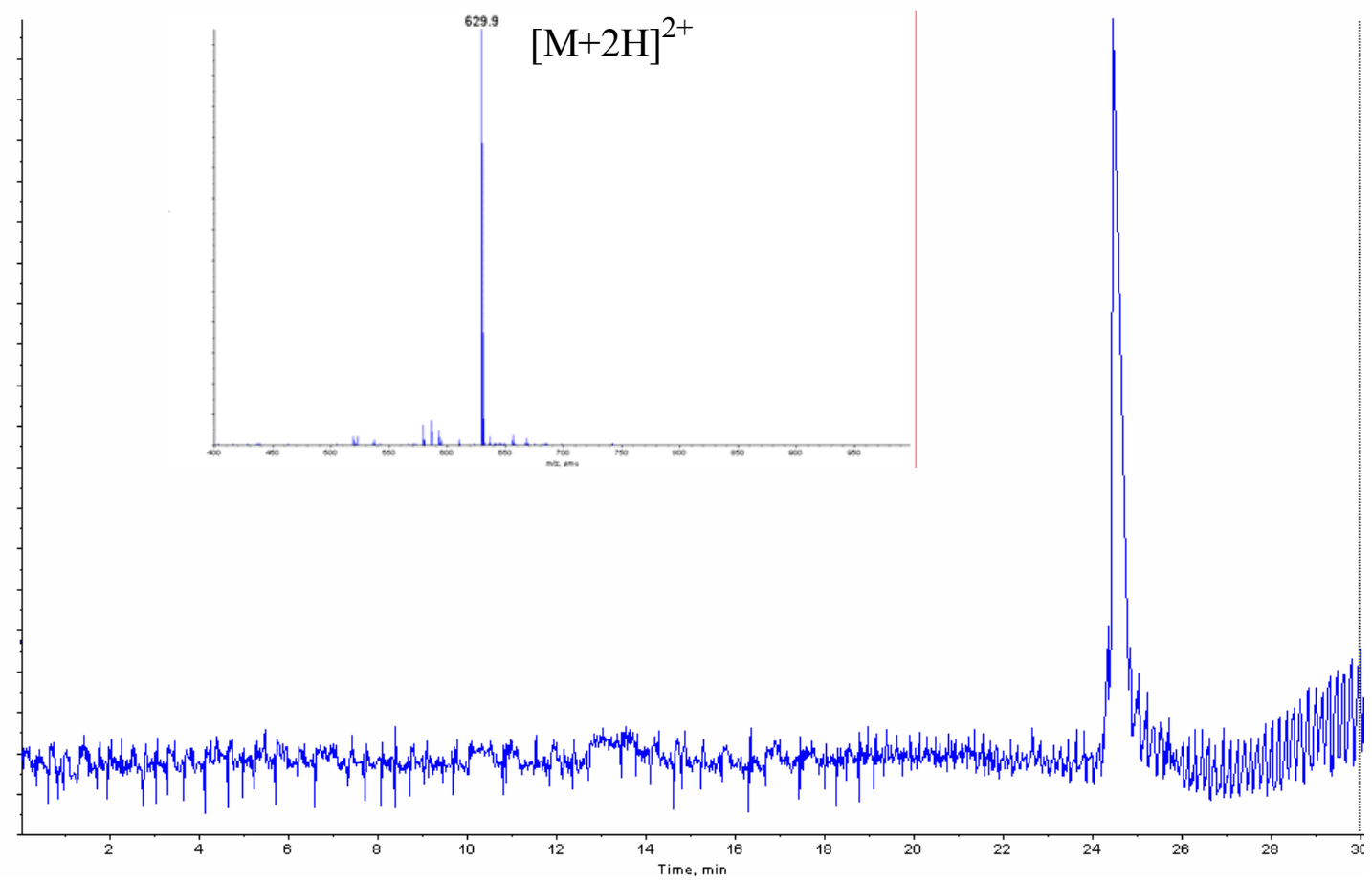

Figure S2. The base peak ion chromatogram of the crude reaction mixture of acylation of 6a (doubly charge ion $\mathrm{m} / \mathrm{z}=629.8$ ) and the full mass spectrum at retention time of $24.5 \mathrm{~min}$ (inset). 


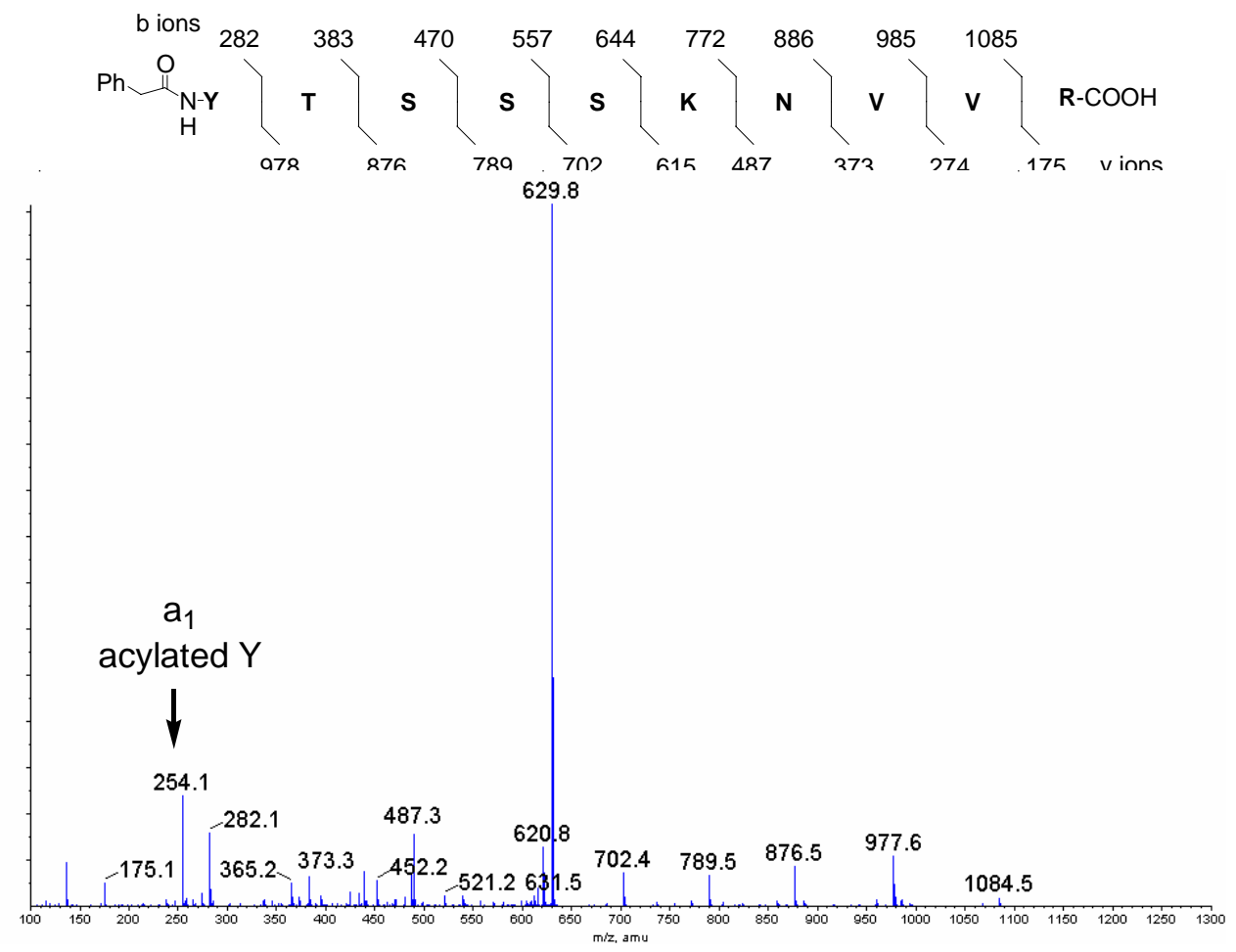

Figure S3. The Q-TOF MS/MS spectrum of the N-terminal acylated peptide 7aa (ESI source, doubly charged ion of $\mathrm{m} / \mathrm{z}=629.8$ ).

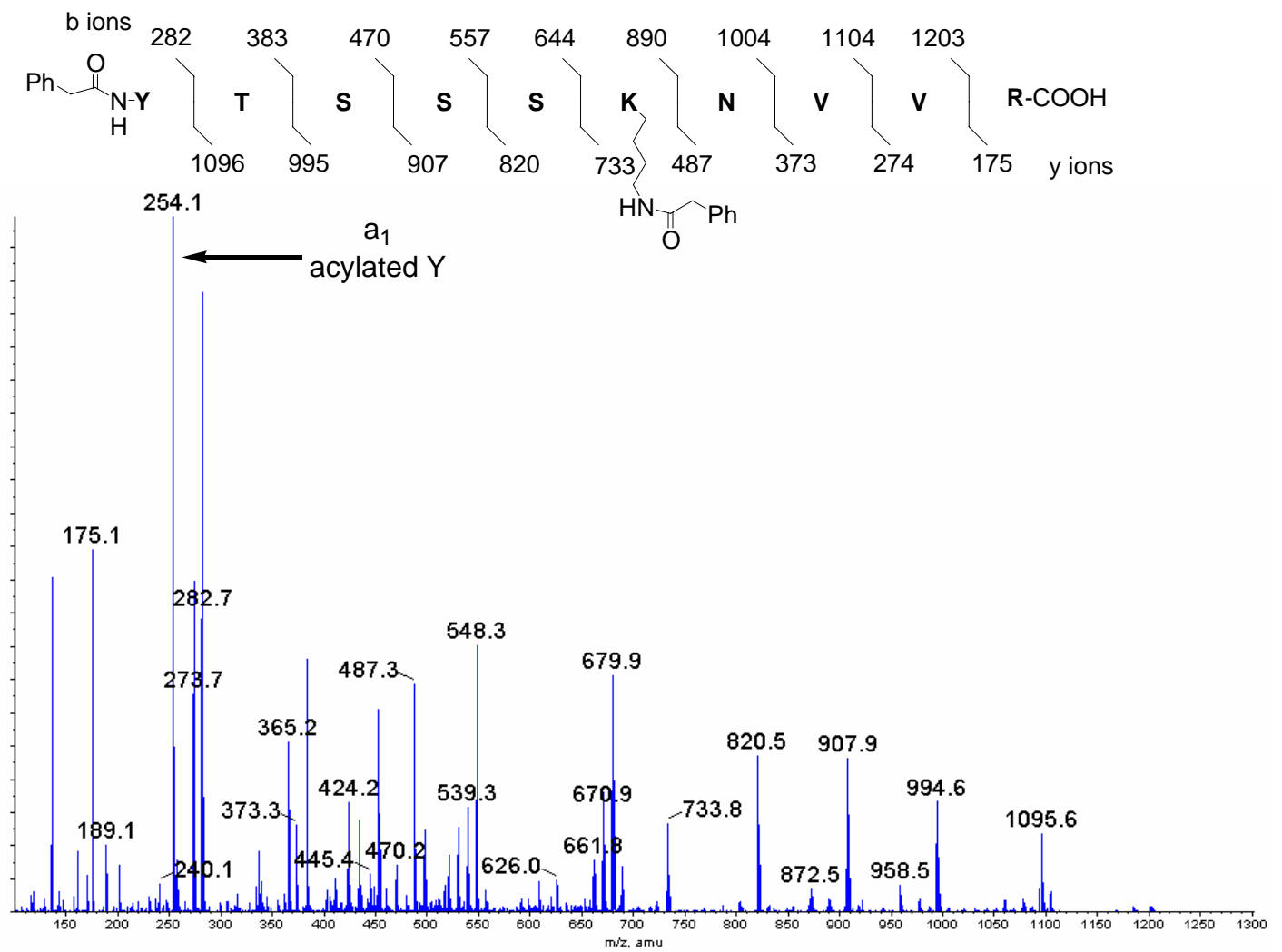

Figure S4. The Q-TOF MS/MS spectrum of diacylated-6a using excess amount of NHS-ester (ESI source, doubly charge ion of $\mathrm{m} / \mathrm{z}=688.8$ ). 


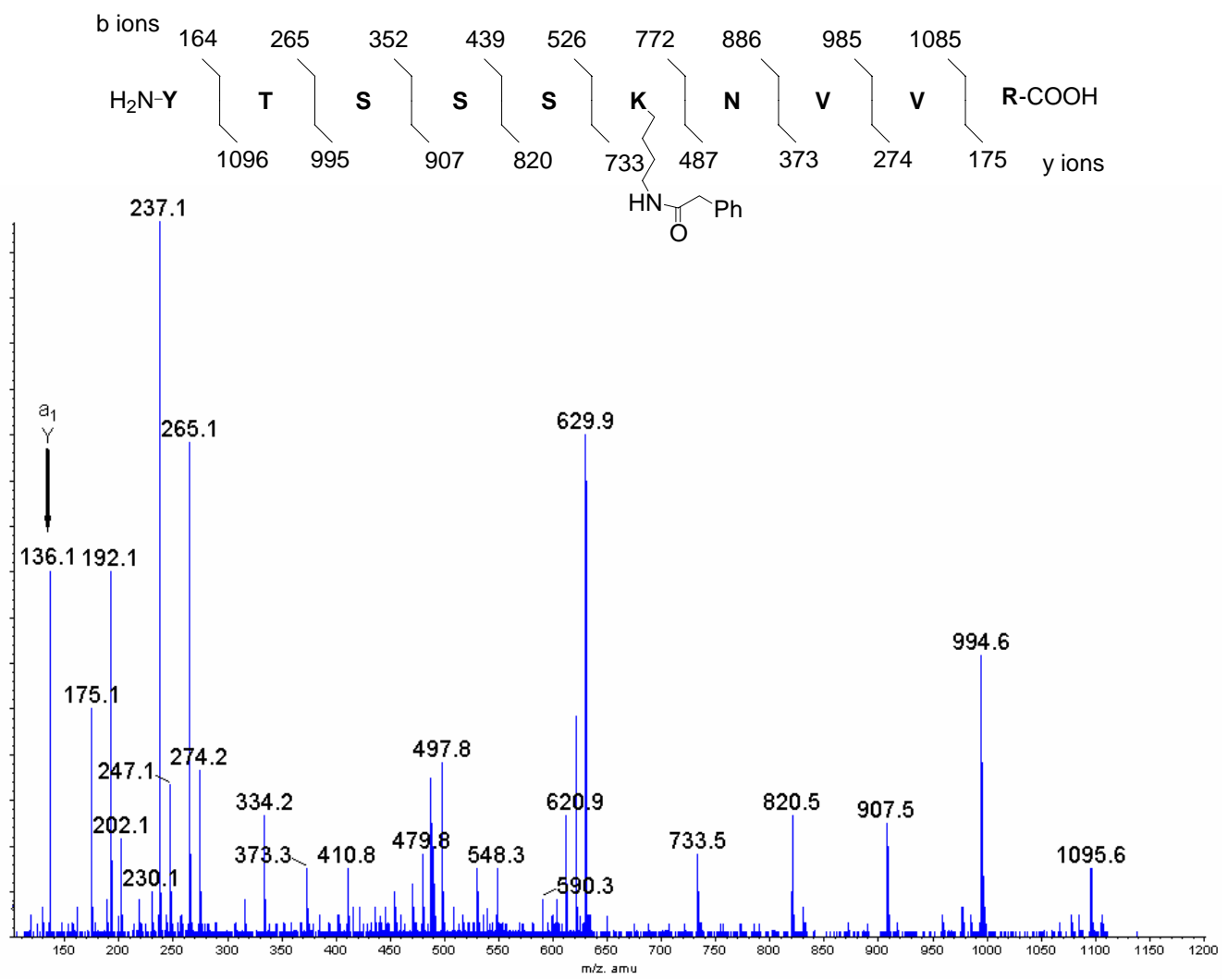

Figure S5. The Q-TOF MS/MS spectrum of the lysine-acylated-6a using stoichiometric amount of NHS-ester (ESI source, doubly charged ion of $\mathrm{m} / \mathrm{z}=629.8$ ).
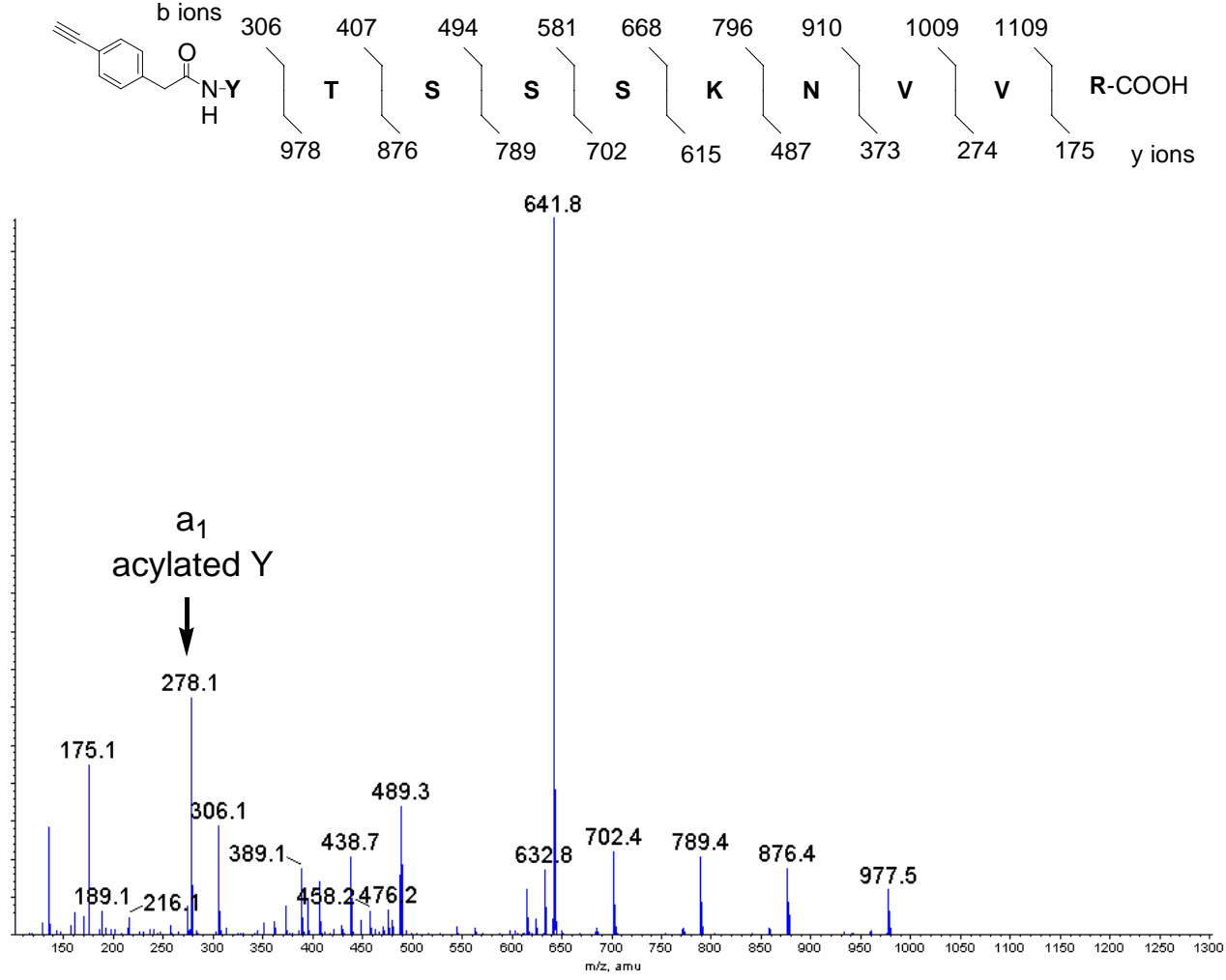

Figure S6. The Q-TOF MS/MS spectrum of the N-terminal acylated peptide 7ab (ESI source, doubly charged ion of $\mathrm{m} / \mathrm{z}=641.8$ ). 


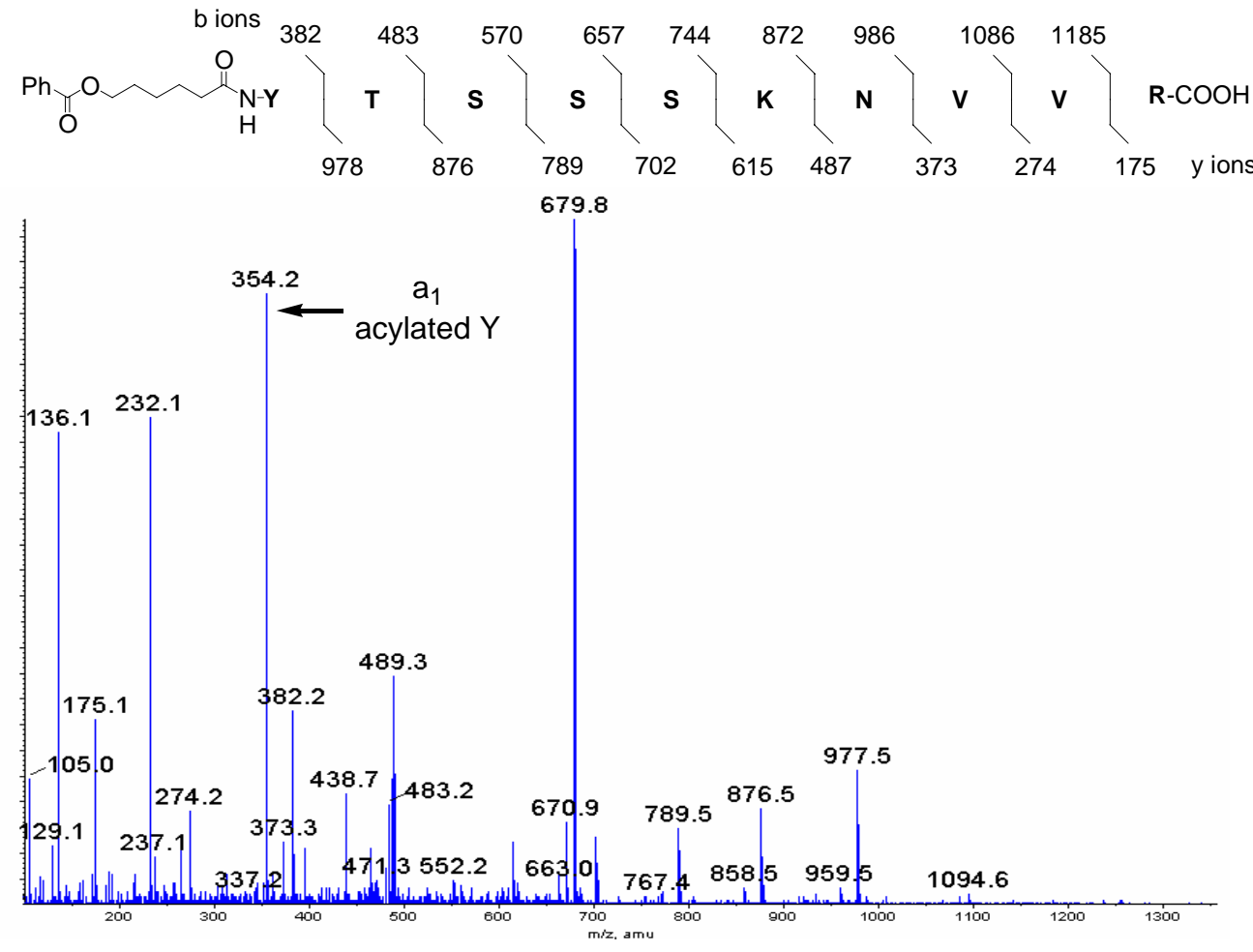

Figure S7. The Q-TOF MS/MS spectrum of the N-terminal acylated peptide 7ac (ESI source, doubly charged ion of $\mathrm{m} / \mathrm{z}=679.9)$.

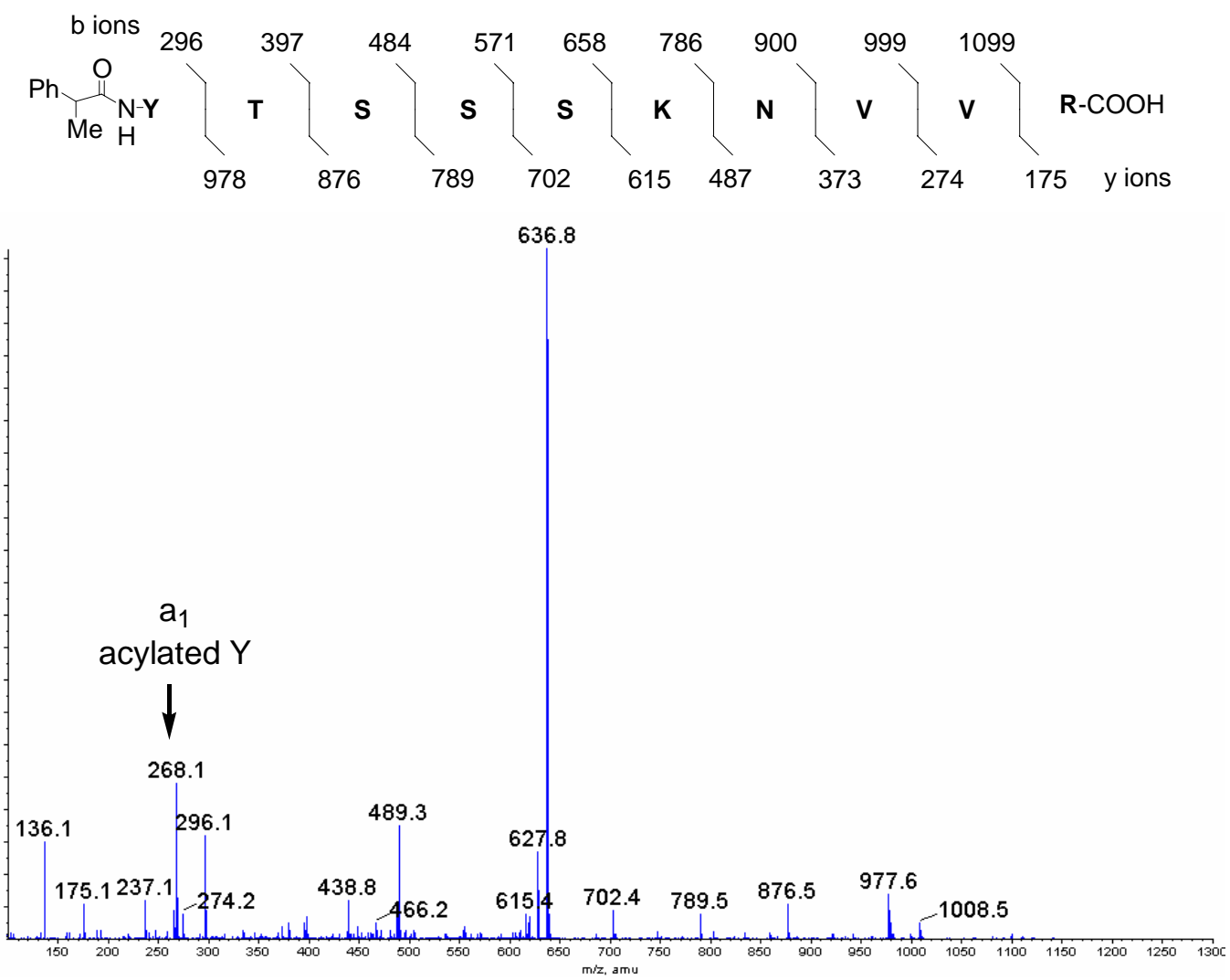

Figure S8. The Q-TOF MS/MS spectrum of the N-terminal acylated peptide 7ad (ESI source, doubly charged ion of $\mathrm{m} / \mathrm{z}=636.8$ ). 


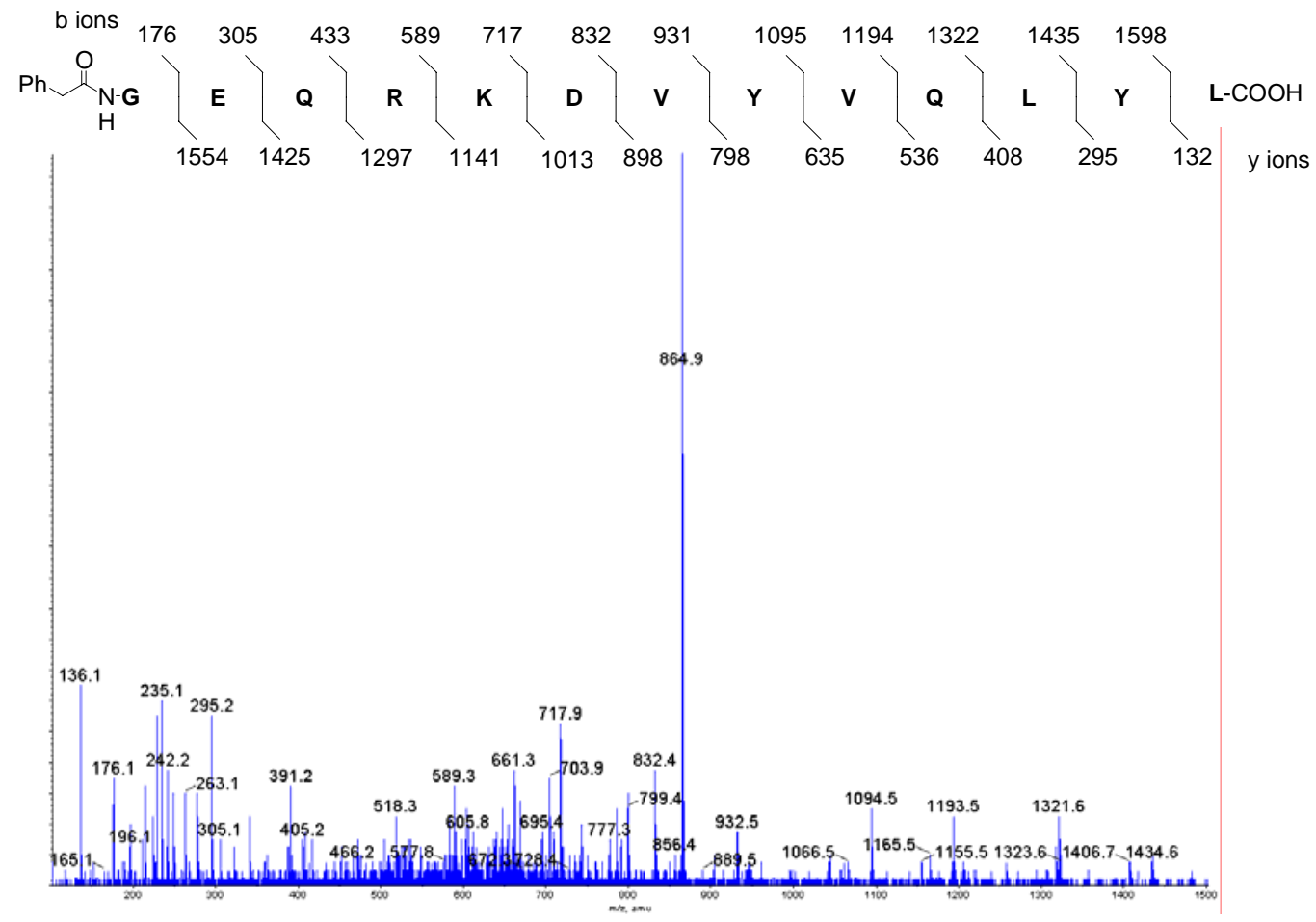

Figure S9. The Q-TOF MS/MS spectrum of the 2a-modified GEQRKDVYVQLYL (ESI source, doubly charged ion of $\mathrm{m} / \mathrm{z}=865.0$ ).

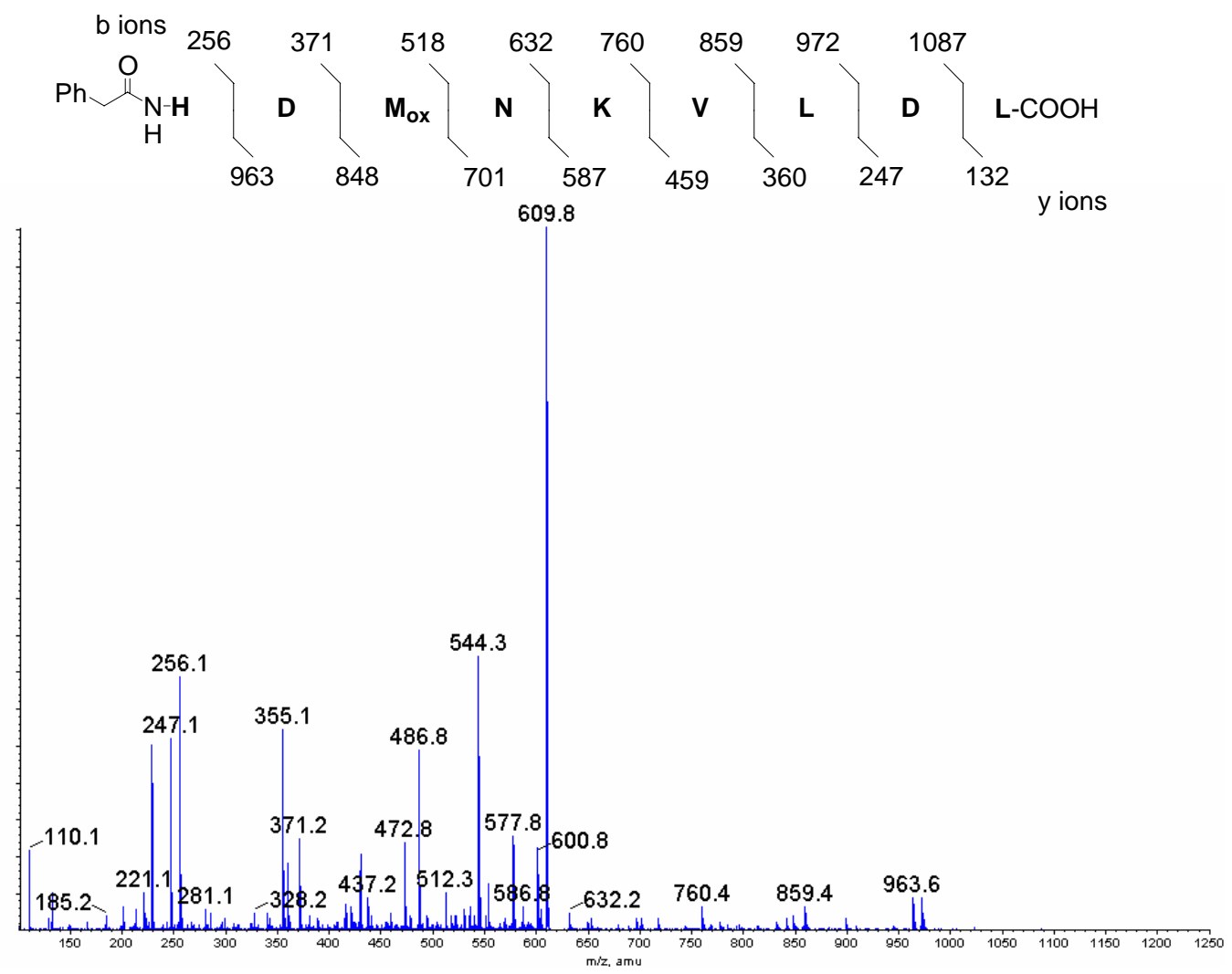

Figure S10. The Q-TOF MS/MS spectrum of the 2a-modified HDM $\mathrm{Ox}_{\mathrm{ox}} \mathrm{NKLDL}\left(\mathrm{M}_{\mathrm{ox}}=\right.$ methionine sulfoxide) (ESI source, doubly charged ion of $\mathrm{m} / \mathrm{z}=609.8$ ). 


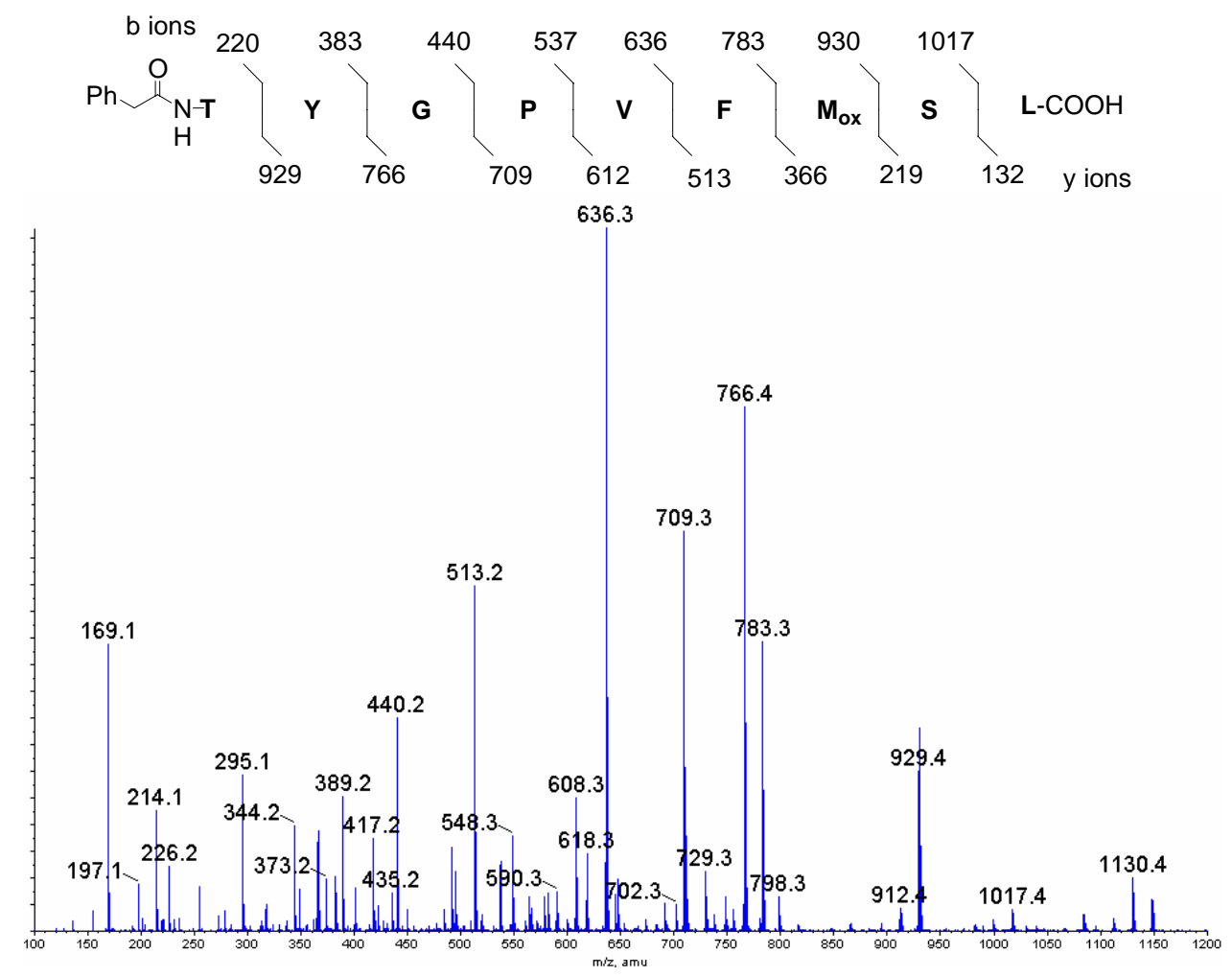

Figure S11. The Q-TOF MS/MS spectrum of the 2a-modified TYGPVFM $_{\mathrm{ox}} \mathrm{SL}\left(\mathrm{M}_{\mathrm{ox}}=\right.$ methionine sulfoxide) (ESI source, singly charged ion of $\mathrm{m} / \mathrm{z}=1148.5$ ).
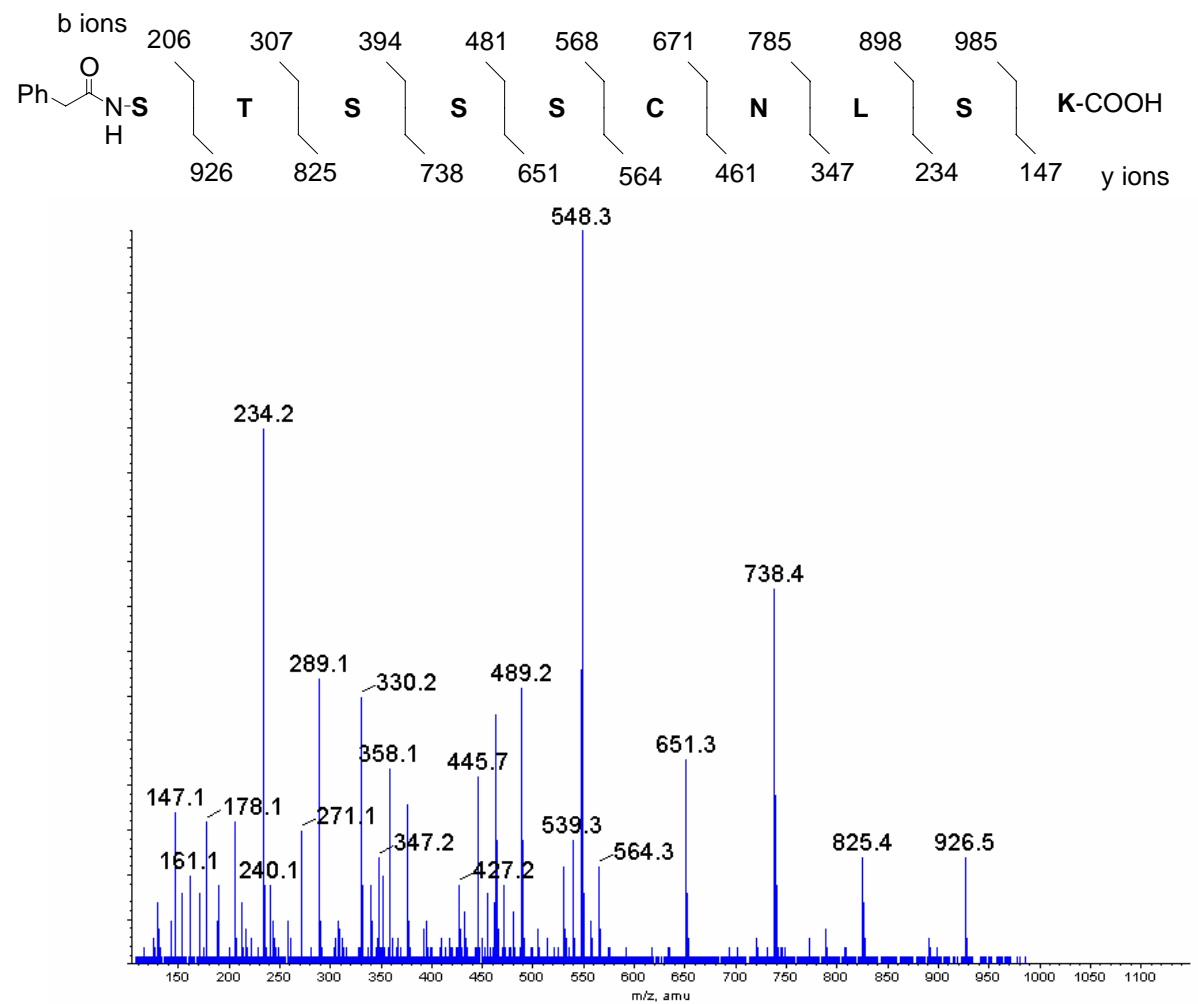

Figure S12. The Q-TOF MS/MS spectrum of the 2a-modified STSSSCNLSK after reduction of the intermolecular disulfide bond by dithiothreitol (DTT) (ESI source, doubly charged ion of $\mathrm{m} / \mathrm{z}=566.2$ ). 


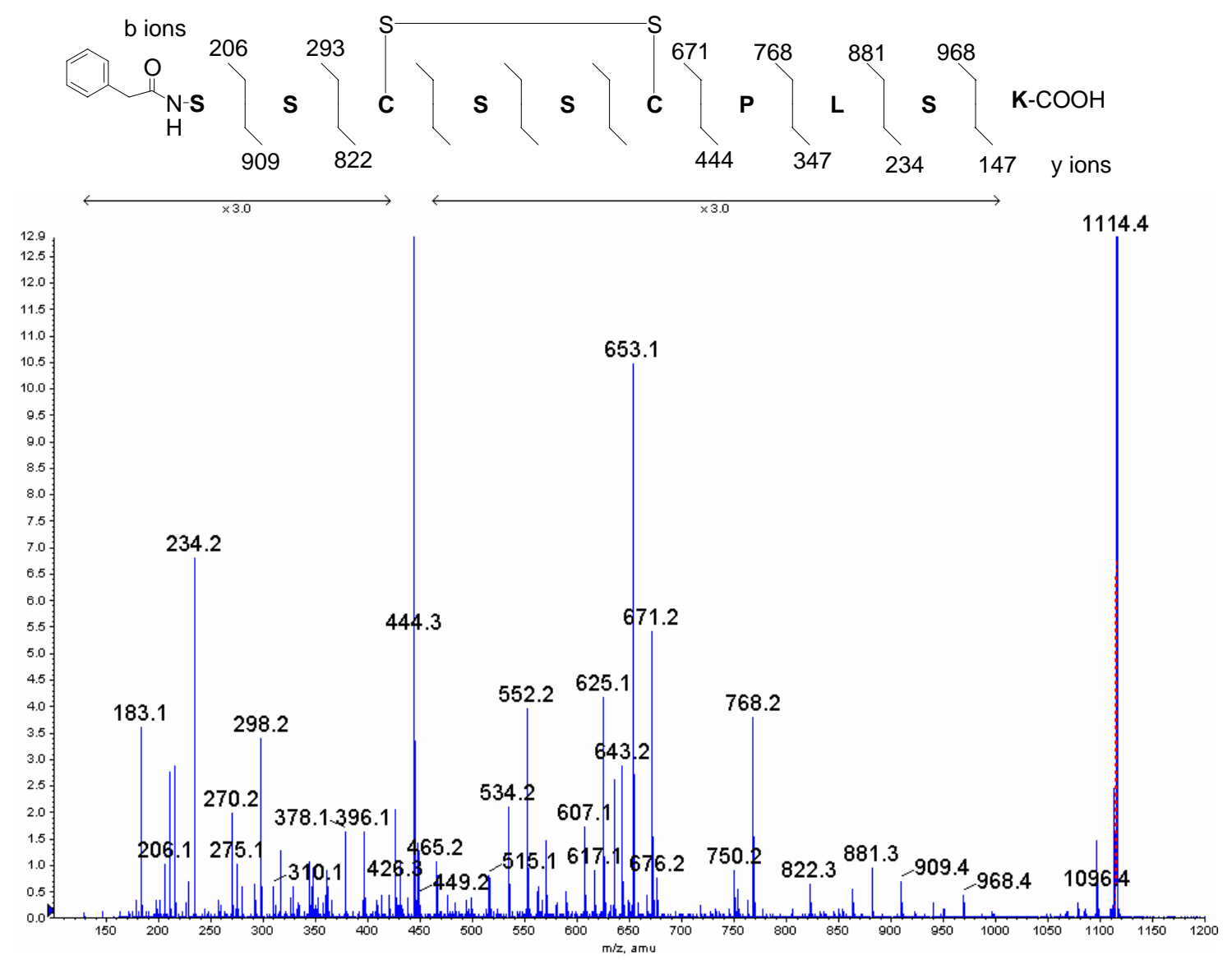

Figure S13. The Q-TOF MS/MS spectrum of the 2a-modified SSCSSCPLSK (intramolecular disulfide-bonded) (ESI source, singly charged ion of $\mathrm{m} / \mathrm{z}=1114.4$ ).
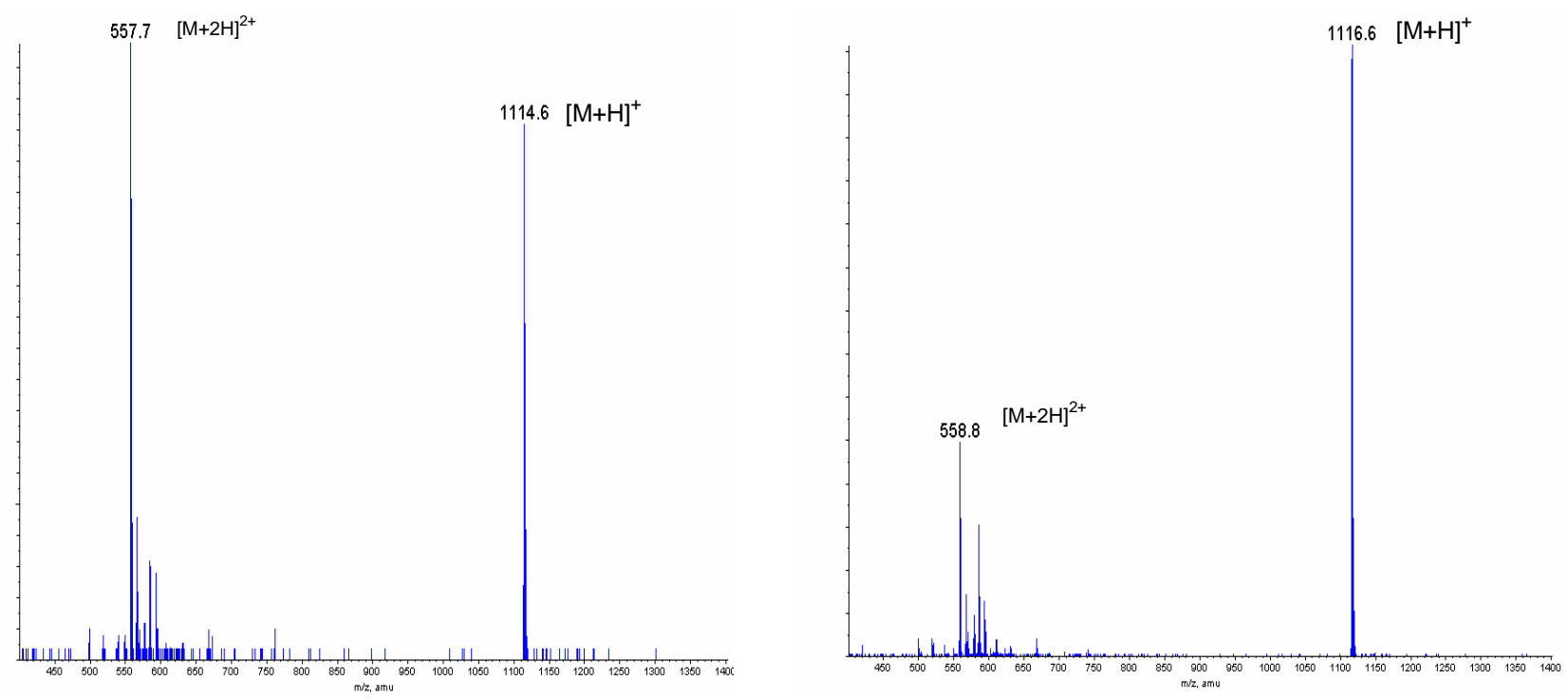

Figure S14. The MS spectrum of 2a-modified SSCSSCPLSK (intramolecular disulfide-bonded, singly charged ion $\mathrm{m} / \mathrm{z}=1114.6$ ) (left) and 2a-modified SSCSSCPLSK (after DTT reduction of intramolecular disulfide bond, singly charged ion $\mathrm{m} / \mathrm{z}=1116.6$ ) (right). 
Apart from the $\alpha$-amino group, the hydroxyl group of terminal serine of peptides STSSSCNLSK and SSCSSCPLSK might also act as a nucleophile to couple with 2a. As the exact molecular structure of the terminal serine of these peptides could not be determined by mass spectrometry, we have conducted the following control experiment to confirm the structure of these peptides. Serine derivative 3e with a free hydroxyl group and a protected $\alpha$-amino group was synthesized and subjected to coupling reaction with 2a under the reaction conditions listed in Table S1. No coupling product was obtained and 3e was completely recovered. Thus, attachment of alkyne $\mathbf{2 a}$ to the $\mathrm{OH}$ group of the terminal serine was ruled out.

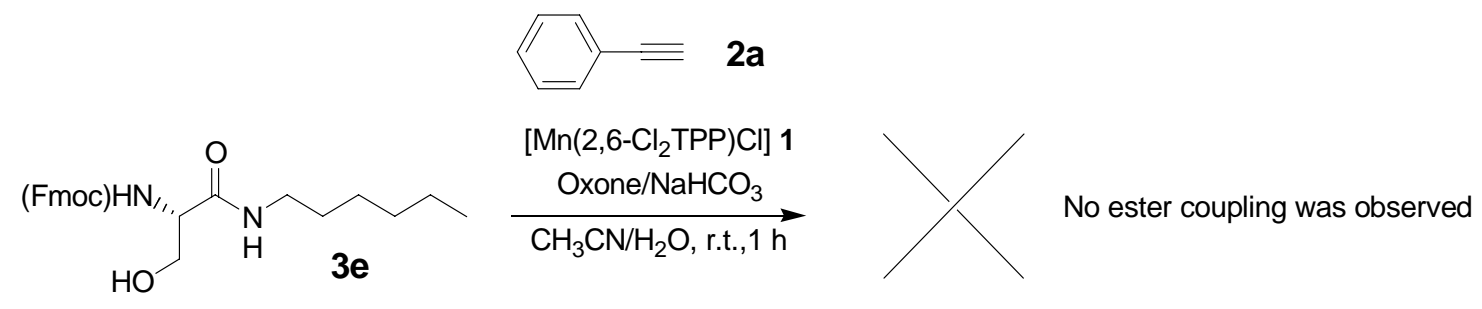


Procedure for Synthesis and Isolation of 2a-Modified SSCSSCPLSK. A solution of peptide SSCSSCPLSK (10 mg), 2a (52 mg), 1 (2 mg), $110 \mu \mathrm{L}$ of $\mathrm{H}_{2} \mathrm{O}_{2}(30 \% \mathrm{v} / \mathrm{v})$ and $\mathrm{NaHCO}_{3}(8 \mathrm{mg})$ in $\mathrm{CH}_{3} \mathrm{CN} / \mathrm{H}_{2} \mathrm{O}(80 \mathrm{~mL}, 3: 2)$ was prepared and placed into two centrifugal tubes (size: $50 \mathrm{~mL}$ ). The reaction mixtures were incubated at $25{ }^{\circ} \mathrm{C}$ for $6 \mathrm{~h}$ and then stored inside a refrigerator overnight. The $\mathrm{CH}_{3} \mathrm{CN}$ layer (reddish brown upper layer) containing 1 and unreacted 2a and aqueous layer (colorless lower layer) containing peptides were separated using a dropper. The combined aqueous phase was freeze-dried and purified by preparative reversed-phase HPLC equipped with a $\mathrm{C}_{18}$ column using $\mathrm{CH}_{3} \mathrm{CN} / \mathrm{H}_{2} \mathrm{O} / \mathrm{TFA}$ as the solvent system. The 2a-modified SSCSSCPLSK (intramolecular disulfidebonded) was isolated at $65 \%$ yield $(5.3 \mathrm{mg})$ based on $81 \%$ conversion. The $81 \%$ conversion is calculated based on the $19 \%$ recovery of unacylated intramolecular disulfide-bonded peptide. The sequence of 2a-modified SSCSSCPLSK (intramolecular disulfide-bonded) was confirmed by MALDITOF and LC-MS/MS analyses. 

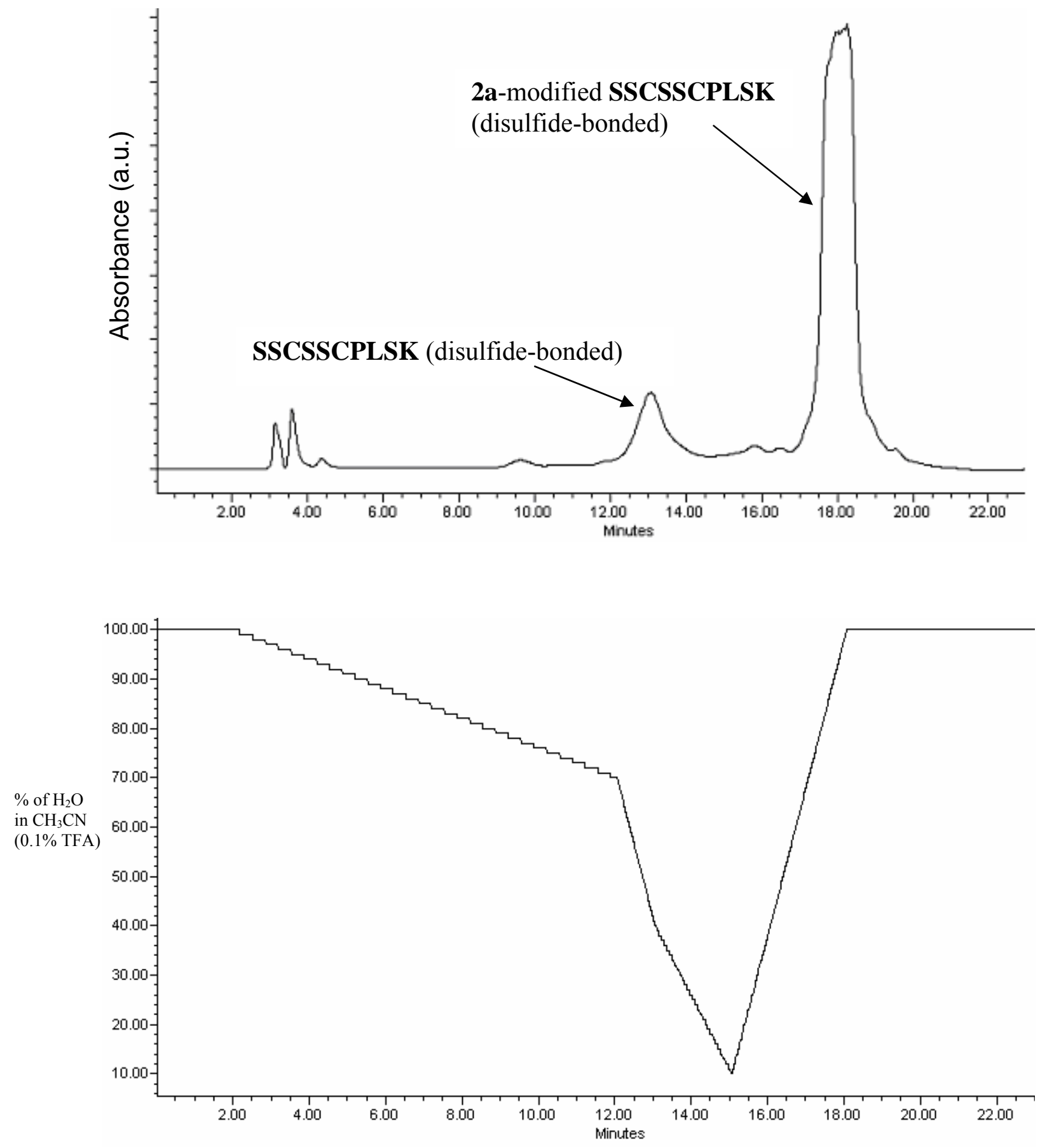

Figure S15. LC chromatogram of reaction mixture of the aqueous phase (upper) and solvent gradient (flow rate: $10 \mathrm{~mL} / \mathrm{min}$ ) used in preparative HPLC purification (lower). 
Procedure for N-terminal Acylation of Peptide A11 with Oxone

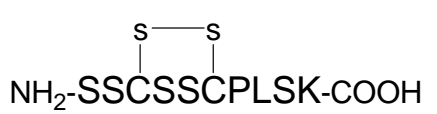

A11
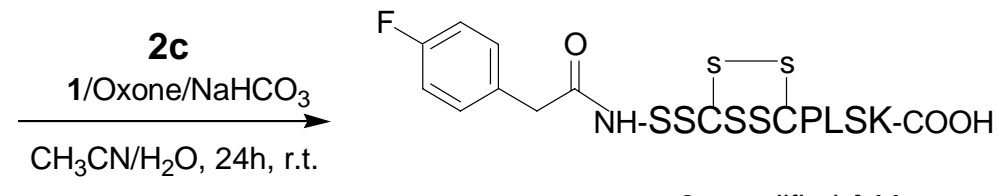

2c-modified A11

In a $1.0 \mathrm{~mL}$ eppendorf tube, $200 \mu \mathrm{L}$ of the $\mathbf{A 1 1}\left(1 \mathrm{mg} / \mathrm{mL}\right.$ in $\left.\mathrm{H}_{2} \mathrm{O}\right), 10 \mu \mathrm{L}$ of $2 \mathbf{c}\left(7 \mathrm{mg} / \mathrm{mL}\right.$ in $\left.\mathrm{CH}_{3} \mathrm{CN}\right)$, $10 \mu \mathrm{L}$ of $1\left(2 \mathrm{mg} / \mathrm{mL}\right.$ in $\left.\mathrm{CH}_{3} \mathrm{CN}\right), 20 \mu \mathrm{L}$ of Oxone/ $\mathrm{NaHCO}_{3}\left(10 \mathrm{mg}\right.$ of Oxone and $4 \mathrm{mg}$ of $\mathrm{NaHCO}_{3}$ in $1 \mathrm{~mL}$ of $\mathrm{H}_{2} \mathrm{O}$ ) and $300 \mu \mathrm{L}$ of $\mathrm{CH}_{3} \mathrm{CN}$ were mixed. The reaction mixture was incubated at $25{ }^{\circ} \mathrm{C}$ for 24 $\mathrm{h}$, and then desalted and concentrated using $\mu \mathrm{C} 18$ ZipTip $^{\circledR}$ pipet tips (Millipore, USA) following the manufacturer's protocol. By MALDI-TOF (Figure S16) and LC-MS/MS (Figure S17) analyses, the structure of 2c-modified A11 was confirmed.

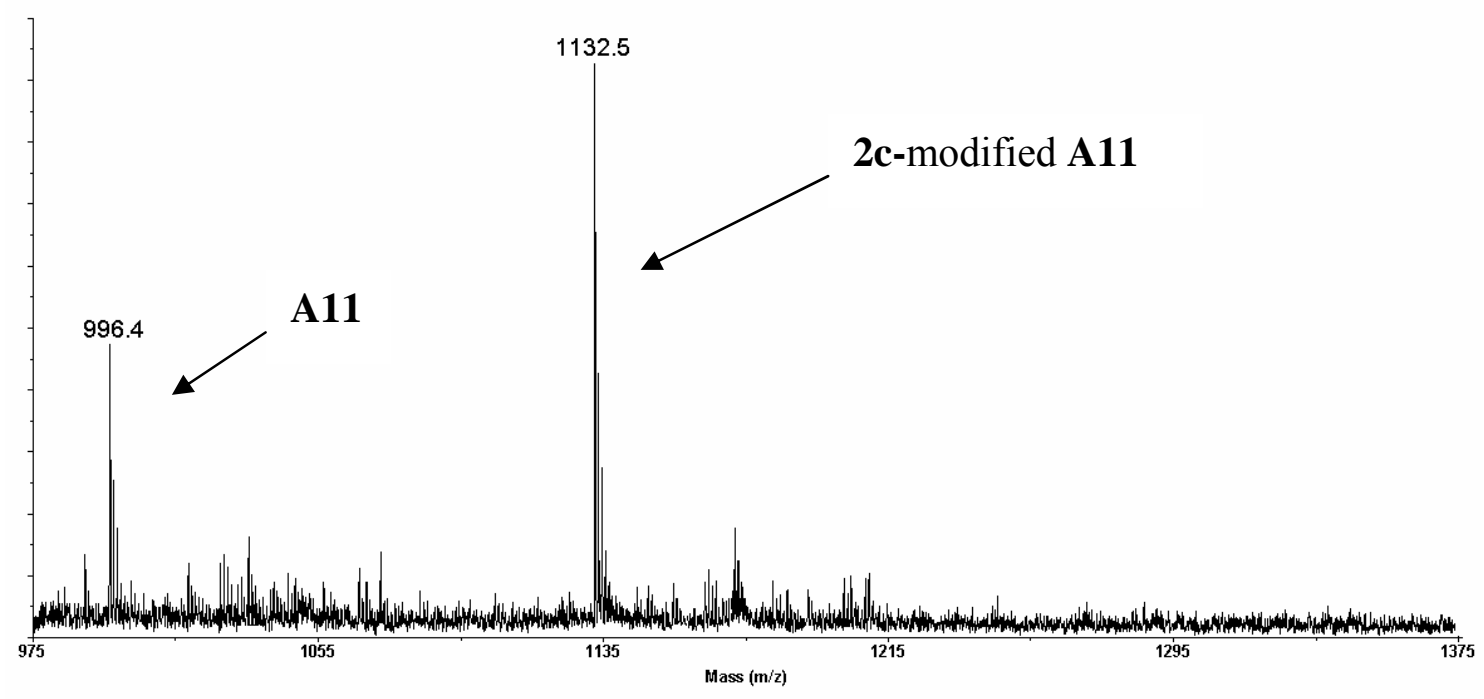

Figure S16. MALDI-TOF mass spectrum of the crude reaction mixture of coupling reaction between A11 and 2c. 


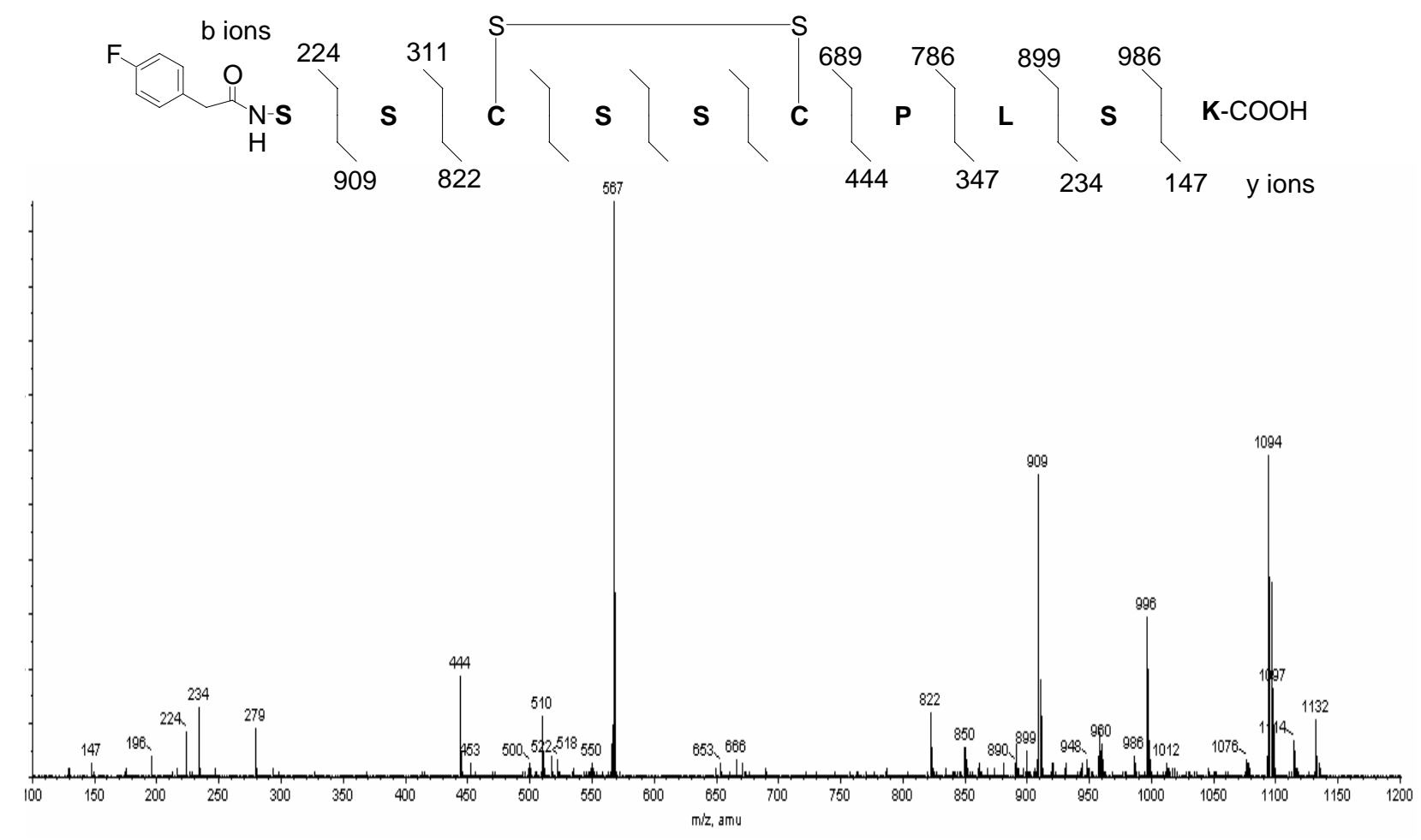

Figure S17. The Q-TOF MS/MS spectrum of the 2c-modified A11 (ESI source, doubly charged ion of $\mathrm{m} / \mathrm{z}=567)$. 


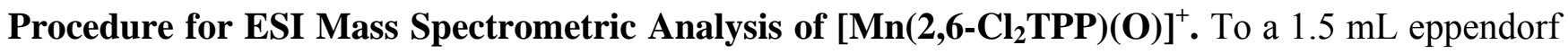
tube, $1(1.5 \mathrm{mg}, 1.5 \mu \mathrm{mol})$ was mixed with Oxone $(1.1 \mathrm{mg}, 1.8 \mu \mathrm{mol})$ and $\mathrm{NaHCO}_{3}(0.48 \mathrm{mg}, 5.8 \mu \mathrm{mol})$ in $\mathrm{CH}_{3} \mathrm{CN}(0.6 \mathrm{~mL})$ and $\mathrm{H}_{2} \mathrm{O}(0.4 \mathrm{~mL})$ for $0.5 \mathrm{~min}$. The reaction mixture was then introduced immediately into the ESI source by a syringe pump through a fused silica capillary tube $(75 \mu \mathrm{m}$ i.d. $20 \mathrm{~cm}$ ) at a flow rate of $3 \mu \mathrm{L} / \mathrm{min}$.

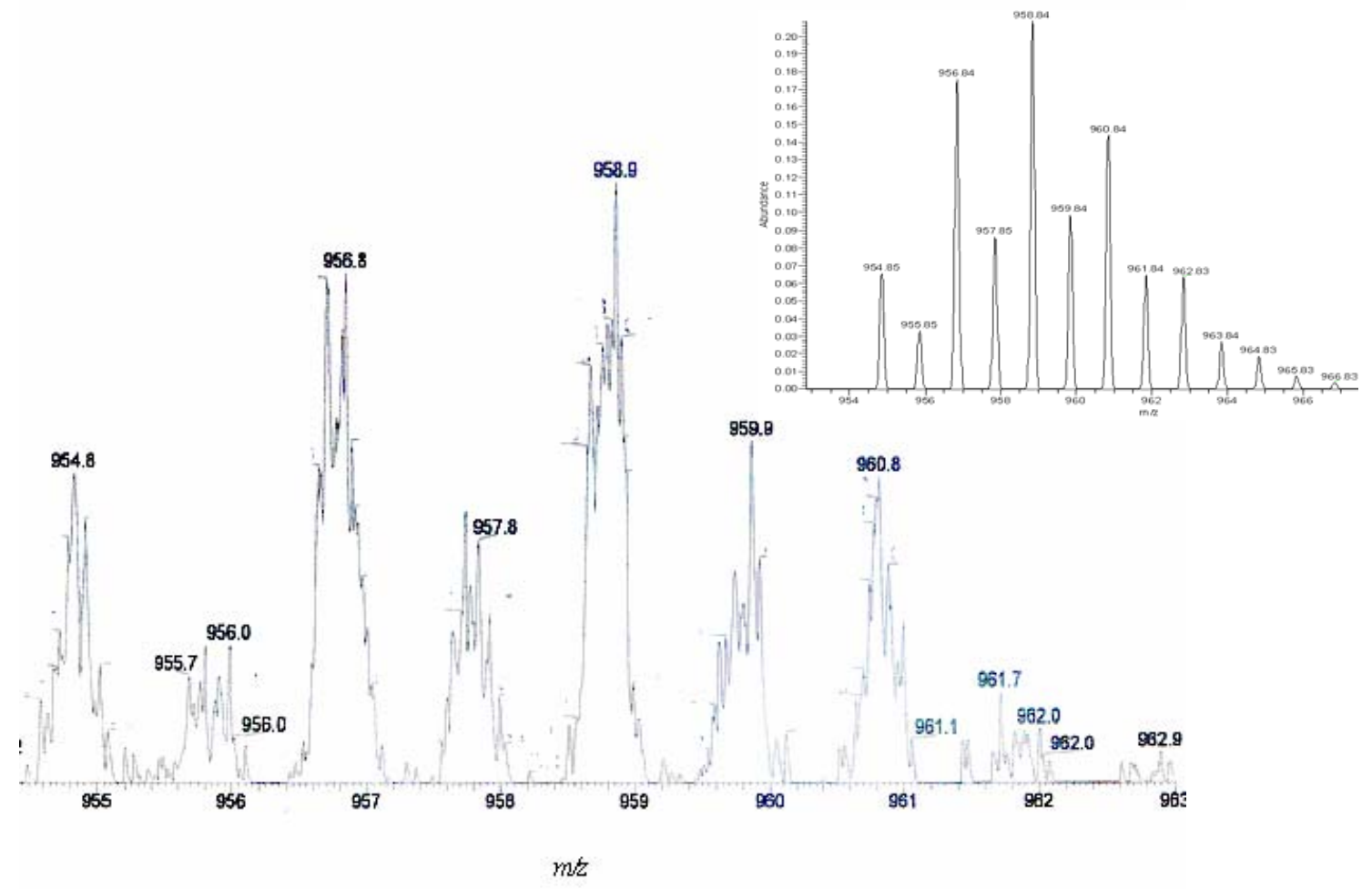

Figure S18. Experimental and calculated (inset) isotopic distribution pattern of $\left[\mathrm{Mn}\left(2,6-\mathrm{Cl}_{2} \mathrm{TPP}\right)(\mathrm{O})\right]^{+}$. 


\section{Investigation on the Origin of N-Terminal Selectivity in Peptide Ligation.}

Selective ligation of $\mathrm{N}$-terminal $\alpha$-amino groups of peptides without modification of lysine $\varepsilon$-amino groups is a great challenge in peptide modification [Lundblad, R. L. Chemical Reagents for Protein

Modification $3^{r d}$ Edition; CRC Press: Florida, 2000]. Owing to the lower $p$ Ka value of the N-terminal $\alpha$-amino group $(p \mathrm{Ka} \sim 8)$ than the lysine $\varepsilon$-amino group $(p \mathrm{Ka} \sim 10)$, ligation of peptides conducted at acidic $\mathrm{pH}(\mathrm{pH} \sim 6)$ may lead to a moderate selectivity of N-terminal ligation [Selo, I.; Negroni, L.; Creminon, C.; Grassi, J.; Wai, J. M. J. Immunol. Methods 1996, 199, 127]. However, the selectivity may vary significantly depending on the sequences of peptides and reaction conditions.

We have conducted the following experiments with an objective to provide a rationale for the Nterminal selectivity in the peptide ligation. For details, please refer to the Supporting Information.

Point 1: The same solvent system is used in the " $1+$ alkynes + Oxone $e^{\mathbb{B}} / \underline{H}_{2} \underline{O}_{2} \underline{\text { ” }}$ method and $N$ hydroxysuccinimide ester method for peptide ligation

The present method using " $1+$ alkynes + Oxone ${ }^{\circledR} / \mathrm{H}_{2} \mathrm{O}_{2}$ " allows $\mathrm{N}$-terminal $\alpha$-amino group ligation of unprotected peptides in $\mathrm{CH}_{3} \mathrm{CN} /$ aqueous $\mathrm{NaHCO}_{3}$ buffer. The $\mathrm{pH}$ of the aqueous $\mathrm{NaHCO}_{3}$ buffer $\left(4 \mathrm{mg} / \mathrm{mL}\right.$ in $\mathrm{H}_{2} \mathrm{O}$ ) was measured to be 8.3 . The coupling reactions of 6 a with $\mathrm{N}$ hydroxysuccinimide ester leading to lysine-acylated peptides were conducted using the same solvent system.

Point 2: No systematic dependence between the reactivity of ketenes and the basicity of amines in acylation

Deuterium scrambling experiments and cross-over scrambling experiments supported the assignment of ketene to be the reactive intermediate in the oxidative amide synthesis reaction. According to literature, there has been no systematic dependence between the reactivity of ketenes and the basicity of amines in acylation [(a) Tidwell, T. T. Ketenes 2nd; Wiley: New York, 2006, section 5.5.2; (b) Andraos, J.; Kresge, A. J. J. Am. Chem. Soc. 1992, 114, 5643].

\section{Point 3: Peptide ligation experiments with phenylketene generated in situ}

According to the literature [Tidwell, T. T. Ketenes 2nd; Wiley: New York, 2006, section 3.3], phenylketene $(\mathrm{PhCH}=\mathrm{C}=\mathrm{O})$ could be generated in situ from photo-Wolff rearrangement of $\alpha$-diazo 
ketone $\left(\mathrm{PhC}(\mathrm{O}) \mathrm{CHN}_{2}\right)$. We have independently generated $\mathrm{PhCH}=\mathrm{C}=\mathrm{O}$ in situ from photo-Wolff rearrangement of $\mathrm{PhC}(\mathrm{O}) \mathrm{CHN}_{2}$. The coupling reactions between peptides and $\mathrm{PhCH}=\mathrm{C}=\mathrm{O}$ have subsequently been examined.

We found that the same N-terminal selectivity obtained in using the " $1+$ alkynes + Oxone ${ }^{\circledR} / \mathrm{H}_{2} \mathrm{O}_{2}$ " protocol was observed in the coupling reactions of in situ generated phenylketene with peptide 6a (YTSSSKNVVR), GEQRKDVYVQLYL and HDMNKVLDL, and the lysine residues remained intact. In this regard, the porphyrin catalyst, oxidizing agents, reaction temperature, and solvent system are unlikely to play a significant role on the N-terminal selectivity.

\section{Point 4: Effect of $\mathrm{pH}$ in peptide ligation with phenylketene generated in situ}

The use of aqueous $\mathrm{NaHCO}_{3}$ buffer $(\mathrm{pH}$ 8.3) is crucial to achieve the $\mathrm{N}$-terminal selectivity in ligation of peptide 6a with phenylketene generated in situ as mixtures of N-terminal-acylated peptide 7aa $(10 \%)$, lysine-acylated peptide $(10 \%)$ and di-acylated peptide $(80 \%)$ were obtained when a more basic aqueous $\mathrm{K}_{2} \mathrm{CO}_{3}$ buffer ( $\mathrm{pH}$ 11.3) was employed. This $\mathrm{pH}$ dependence is an inherent activity of ketenes in peptide ligation.

\section{Point 5: Competitive coupling reactions between hexyl amine and tyrosine-OCH$\underline{3}_{3}$ with} phenylketene generated in situ

Competitive coupling reactions between hexyl amine and tyrosine- $\mathrm{OCH}_{3}$ with in situ generated phenylketene indicated that hexyl amine is more reactive than the terminal amine of tyrosine- $\mathrm{OCH}_{3}$. This result is just opposite to the N-terminal selectivity observed in peptide ligation.

\section{Point 6: Structure of peptide 6a in solution}

We suggested that secondary structures of peptide 6a in solution could be the reason to account for the N-terminal selectivity. We support this claim with the following CD and 2D-NMR studies on peptide 6a.

The CD spectrum was characterized by one negative minimum at $197 \mathrm{~nm}$, indicating the presence of secondary structures. The CD spectrum was deconvoluted using the CDPro software. The $\alpha-$ helical, $\beta$-sheet and turn content of peptide 6a was estimated to be 21.7, 6.6 and 12.6\%, respectively, with $59.1 \%$ of random coil. 
On the basis of the NOESY spectrum of 6a $\left(\mathrm{H}_{2} \mathrm{~N}-\mathrm{YTSSSKNVVR}-\mathrm{CO}_{2} \mathrm{H}\right)$, an inter residue NOE signal was observed between $\mathrm{K} 6 \mathrm{NH}$ proton and $\mathrm{Y} 1$ phenyl ring proton, indicating that the distance between these protons was less than $5 \AA$.

The steric environment of the N-terminal amino group and the lysine amino group in peptide $6 \mathbf{a}$ in solution may be different from that of simple amines and amino acids. The solution conformation of peptide 6a may in part contribute to the N-terminal selectivity in ligation. 
(a) N-Terminal $\alpha$-Amino Group Ligation of Peptides with in situ Generated Phenylketene $(\mathrm{PhCH}=\mathrm{C}=\mathrm{O})$.

- The solvent system $\left(\mathrm{CH}_{3} \mathrm{CN} / \mathrm{H}_{2} \mathrm{O}\right)$ and aqueous $\mathrm{NaHCO}_{3}$ buffer employed in the following experiments are the same as that used in the " $1+$ alkynes + Oxone ${ }^{\circledR} / \mathrm{H}_{2} \mathrm{O}_{2}$ " ligation reactions.

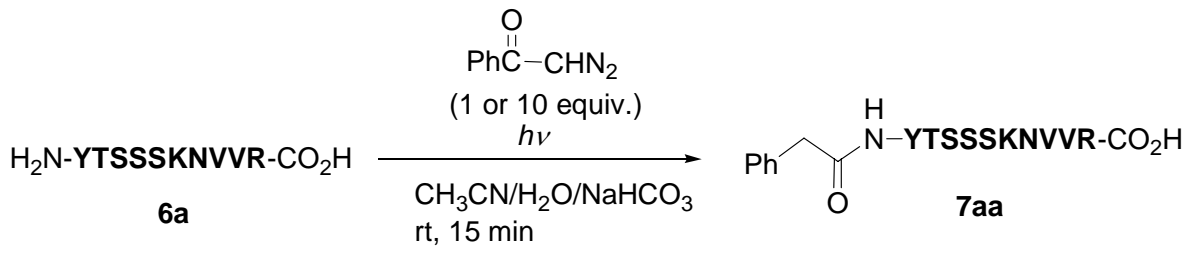

In a quartz curette, $100 \mu \mathrm{L}$ of $6 \mathbf{6 a}\left(1 \mathrm{mg} / \mathrm{mL}\right.$ in $\left.\mathrm{H}_{2} \mathrm{O}\right), 100 \mu \mathrm{L}$ of $\mathrm{PhC}(\mathrm{O}) \mathrm{CHN}_{2}(10$ equiv.; $1 \mathrm{mg} / \mathrm{mL}$ in $\left.\mathrm{CH}_{3} \mathrm{CN}\right)$ and $20 \mu \mathrm{L}$ of $\mathrm{NaHCO}_{3}\left(4 \mathrm{mg} / \mathrm{mL}\right.$ in $\mathrm{H}_{2} \mathrm{O}$, pH 8.3) in $860 \mu \mathrm{L}$ of $\mathrm{CH}_{3} \mathrm{CN} / \mathrm{H}_{2} \mathrm{O}(3: 2)$ were mixed. The reaction mixture was irradiated under a Xenon lamp (300 W Xenon lamp, operating from an Oriel Model 68811 arc lamp power supply) at room temperature. The Xenon light was passed first through a 5-cm water-jacketed sample cell. After $15 \mathrm{~min}$ of irradiation, peptide 7aa was detected as the only product with complete conversion as confirmed by LC-MS analysis. LC-MS/MS analysis of 7aa confirmed that the $\mathrm{N}$-terminal $\alpha$-amino group of $\mathbf{6 a}$ was acylated without modification of the side chains of tyrosine, threonine, serine and lysine. Using 1 equivalent of $\mathrm{PhC}(\mathrm{O}) \mathrm{CHN}_{2}$, 7aa was also obtained as the sole product with $c a$. $30 \%$ conversion of $\mathbf{6 a}$.

A model study using tyrosine- $\mathrm{OCH}_{3}$ was conducted to provide evidence for the structure of peptide 7aa.

Procedure: Tyrosine-

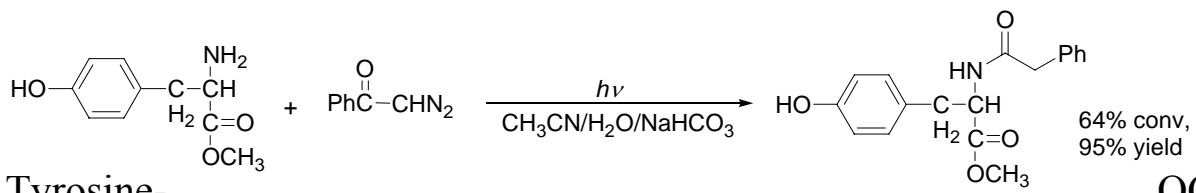

$\mathrm{OCH}_{3} \quad \mathrm{OCH}_{3}(20 \mu \mathrm{mol})$

in an $1 \mathrm{~mL} \mathrm{CH} \mathrm{CN}_{3} \mathrm{CH} \mathrm{H}_{2} \mathrm{O}$ (3:2) solution containing $20 \mu \mathrm{l}$ of $\mathrm{NaHCO}_{3}\left(4 \mathrm{mg} / \mathrm{mL}\right.$ in $\mathrm{H}_{2} \mathrm{O}$, pH 8.3) was treated with $\mathrm{PhC}(\mathrm{O}) \mathrm{CHN}_{2}$ (1 equiv.) in a quartz curette at room temperature under Xenon lamp irradiation. After $15 \mathrm{~min}$ of irradiation, 1,4-dibromobenzene was added as an internal standard to the reaction mixture and the organic compounds were analyzed by GC-MS (Agilent 6890N and 5973N) using a HP-5 column. The yield of the product $\left(\mathrm{PhCH}_{2} \mathrm{C}(\mathrm{O}) \mathrm{NH}\right.$-tyrosine- $\left.\mathrm{OCH}_{3}\right)$ [Tetrahedron Lett. 2004, 45, 9649] was determined as $95 \%$ based on $64 \%$ conversion of tyrosine- $\mathrm{OCH}_{3}$.

Under the same reaction conditions, N-terminal acylations of other two peptides [GEQRKDVYVQLYL and HDMNKVLDL] with in situ generated phenylketene $(\mathrm{PhCH}=\mathrm{C}=\mathrm{O})$ were also achieved without modification of the lysine residues. 
(b) Use of Aqueous $\mathrm{K}_{2} \underline{\mathrm{CO}}_{3}$ Buffer for Peptide Modification with in situ Generated Phenylketene $(\mathrm{PhCH}=\mathrm{C}=\mathrm{O})$.

In a quartz curette, $100 \mu \mathrm{L}$ of $\mathbf{6 a}\left(1 \mathrm{mg} / \mathrm{mL}\right.$ in $\left.\mathrm{H}_{2} \mathrm{O}\right), 100 \mu \mathrm{L}$ of $\mathrm{PhC}(\mathrm{O}) \mathrm{CHN}_{2}$ (10 equiv.; $1 \mathrm{mg} / \mathrm{mL}$ in $\left.\mathrm{CH}_{3} \mathrm{CN}\right)$ and $20 \mu \mathrm{L}$ of $\mathrm{K}_{2} \mathrm{CO}_{3}\left(6.9 \mathrm{mg} / \mathrm{mL}\right.$ in $\mathrm{H}_{2} \mathrm{O}$, pH 11.3) in $860 \mu \mathrm{L}$ of $\mathrm{CH}_{3} \mathrm{CN} / \mathrm{H}_{2} \mathrm{O}$ (3:2) were mixed. The reaction mixture was irradiated under a Xenon lamp (300 W Xenon lamp, operating from an Oriel Model 68811 arc lamp power supply) at room temperature. The Xenon light was passed first through a 5-cm water-jacketed sample cell. After 15 min of irradiation, a mixture of N-terminal acylated peptide 7aa (10\%), lysine-acylated peptide (10\%) and di-acylated peptide (80\%) was detected by LC-MS/MS analysis (yields were based on peak areas of each product).

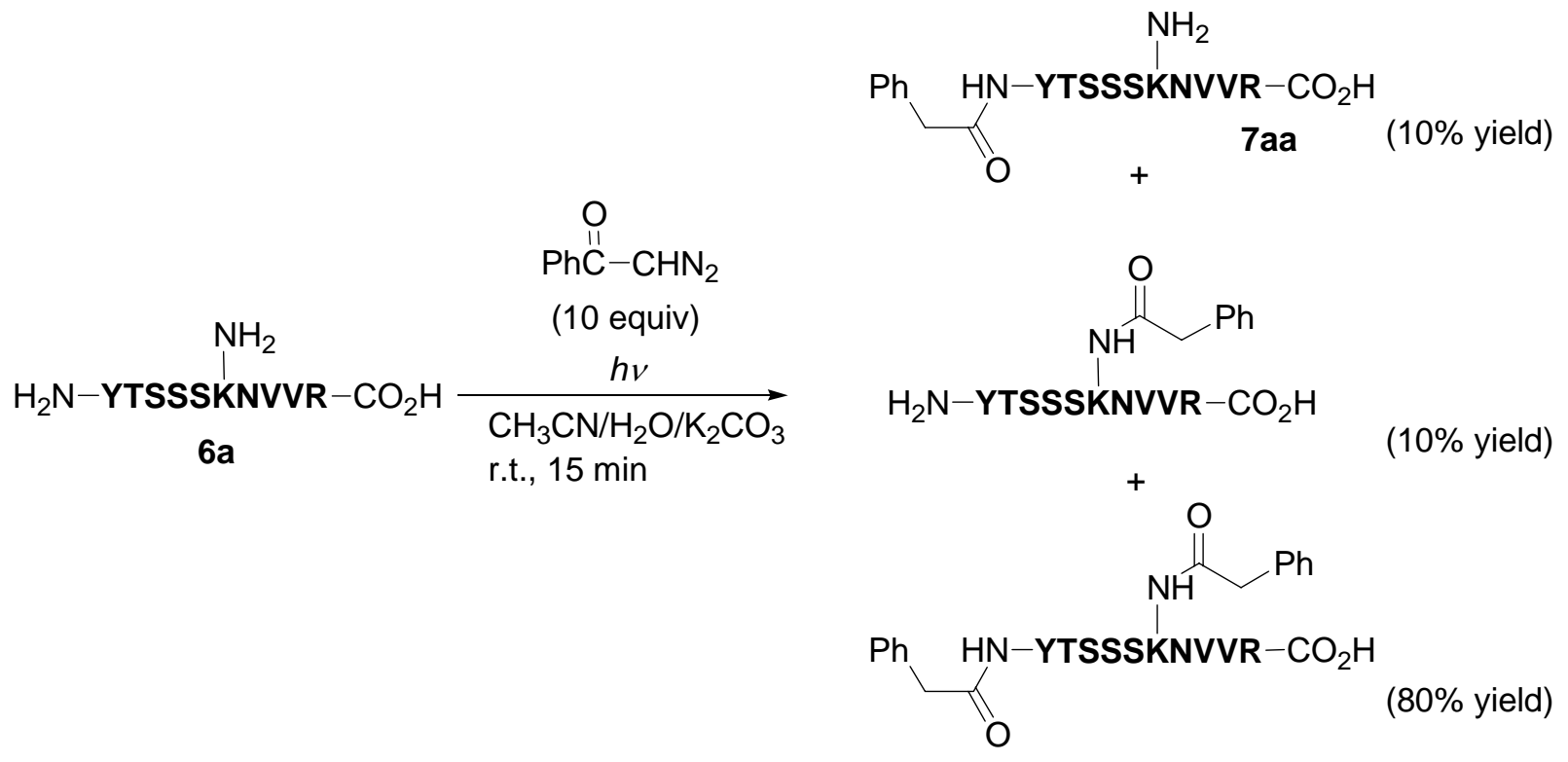


(c) Competitive Coupling Reactions of Hexyl Amine and Tyrosine- $\mathrm{OCH}_{3}$ with in situ Generated Phenylketene $(\mathrm{PhCH}=\mathrm{C}=\mathrm{O})$.

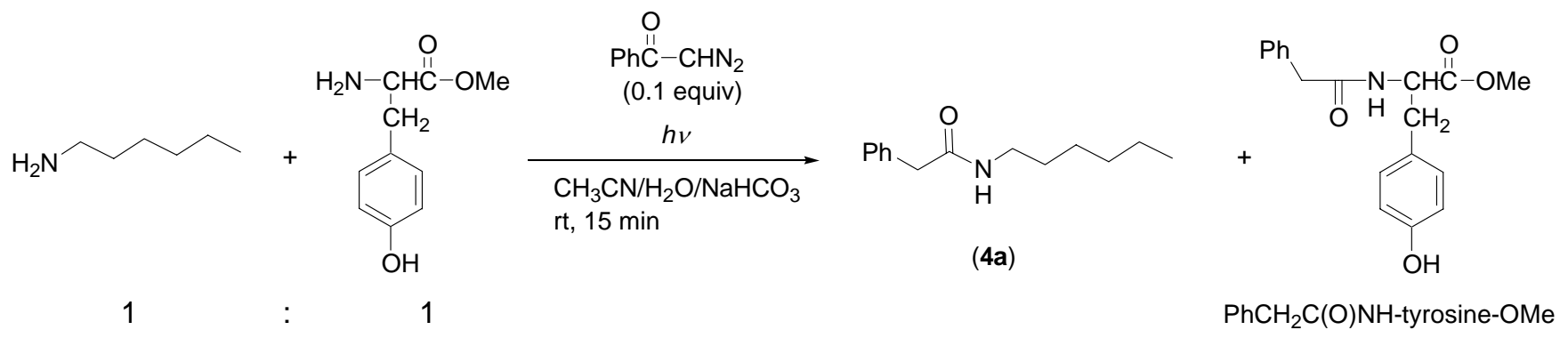

Hexyl amine $(50 \mu \mathrm{mol})$ and tyrosine- $\mathrm{OCH}_{3}(50 \mu \mathrm{mol})$ in an $1 \mathrm{~mL} \mathrm{CH} \mathrm{CH}_{3} \mathrm{CN} / \mathrm{H}_{2} \mathrm{O}(3: 2)$ solution containing $20 \mu \mathrm{L}$ of $\mathrm{NaHCO}_{3}\left(4 \mathrm{mg} / \mathrm{mL}\right.$ in $\left.\mathrm{H}_{2} \mathrm{O}, \mathrm{pH} 8.3\right)$ was treated with a limited amount of $\mathrm{PhC}(\mathrm{O}) \mathrm{CHN}_{2}(0.1$ equiv.) in a quartz curette at room temperature under Xenon lamp irradiation (300 W Xenon lamp, operating from an Oriel Model 68811 arc lamp power supply). The Xenon light was passed first through a 5-cm water-jacketed sample cell. After $15 \mathrm{~min}$ of irradiation, the reaction mixture was analyzed by GC-MS (Agilent 6890N and 5973N) using a HP-5 column.

The product ratio of $4 \mathrm{a}$ to $\mathrm{PhCH}_{2} \mathrm{C}(\mathrm{O}) \mathrm{NH}$-tyrosine- $\mathrm{OCH}_{3}$ was found to be $5.4: 1$, indicating that hexyl amine is more reactive than the terminal amine of tyrosine- $\mathrm{OCH}_{3}$ in the coupling reaction with phenylketene.

Similar product ratio $\left(4 a\right.$ : $\mathrm{PhCH}_{2} \mathrm{C}(\mathrm{O}) \mathrm{NH}$-tyrosine- $\left.\mathrm{OCH}_{3}=6: 1\right)$ was found when the competitive coupling reaction was conducted using the " $\mathbf{1} / \mathbf{2 a} / \mathrm{Oxone} / \mathrm{NaHCO}_{3}$ " protocol [(Oxone $(0.03 \mathrm{mmol})$ and $\left.\mathrm{NaHCO}_{3}(0.093 \mathrm{mmol})\right]$. 


\section{(d) Circular Dichroism Spectropolarimetry Studies of Peptide 6a}

Far-UV CD spectroscopy was performed at room temperature on a Jasco J-720 spectropolarimeter using a quartz cuvette with a path length of $0.1 \mathrm{~mm}$. The data were recorded range from 190 to $260 \mathrm{~nm}$ in a step of $0.1 \mathrm{~nm}$, with scan speed of $50 \mathrm{~nm} / \mathrm{min}$. 40 scans were averaged for each spectrum, and the reference spectra of the respective media were abstracted. Molar ellipticity values were calculated according to the equation $([\theta]=\theta / 10 l c n)$, where $\theta$ is the ellipticity in millidegrees, $l$ is the path length in centimeters, $c$ is the molar concentration of the peptide, and $n$ is the number of amino acid residues of the peptide. The $\alpha$-helix, $\beta$-sheet and turn content was estimated using the CONTINLL program [Provencher, S. W.; Glockner, J. Biochemistry 1981, 20, 33; van Stokkum, I. H.; Spoelder, H. J.; Bloemendal, M.; can Grondelle, R.; Groen, F. Anal. Biochem. 1990, 191, 110] from the CDPro software package [Sreerama, N; Woody, R. W. Anal Biochem. 2000, 287, 252].

Procedure: In a $1.0 \mathrm{~mL}$ eppendorf tube, $50 \mu \mathrm{L}$ of 6 a $\left(1 \mathrm{mg} / \mathrm{mL}\right.$ in $\left.\mathrm{H}_{2} \mathrm{O}\right), 10 \mu \mathrm{L}$ of $\mathrm{NaHCO}_{3}(4 \mathrm{mg} / \mathrm{mL}$ in $\mathrm{H}_{2} \mathrm{O}, \mathrm{pH} 8.3$ ) and $430 \mu \mathrm{L}$ of $\mathrm{CH}_{3} \mathrm{CN} / \mathrm{H}_{2} \mathrm{O}(3: 2)$ were mixed. The solution was transferred to the quartz cuvette and was subjected to far-UV CD spectroscopy analysis (Figure S19). The CD spectrum was characterized by one negative minimum at $197 \mathrm{~nm}$, indicating the presence of secondary structures. The CD spectrum was deconvoluted using the CDPro software. The $\alpha$-helical, $\beta$-sheet and turn content of peptide 6a was estimated to be 21.7, 6.6 and 12.6\%, respectively, with $59.1 \%$ of random coil.

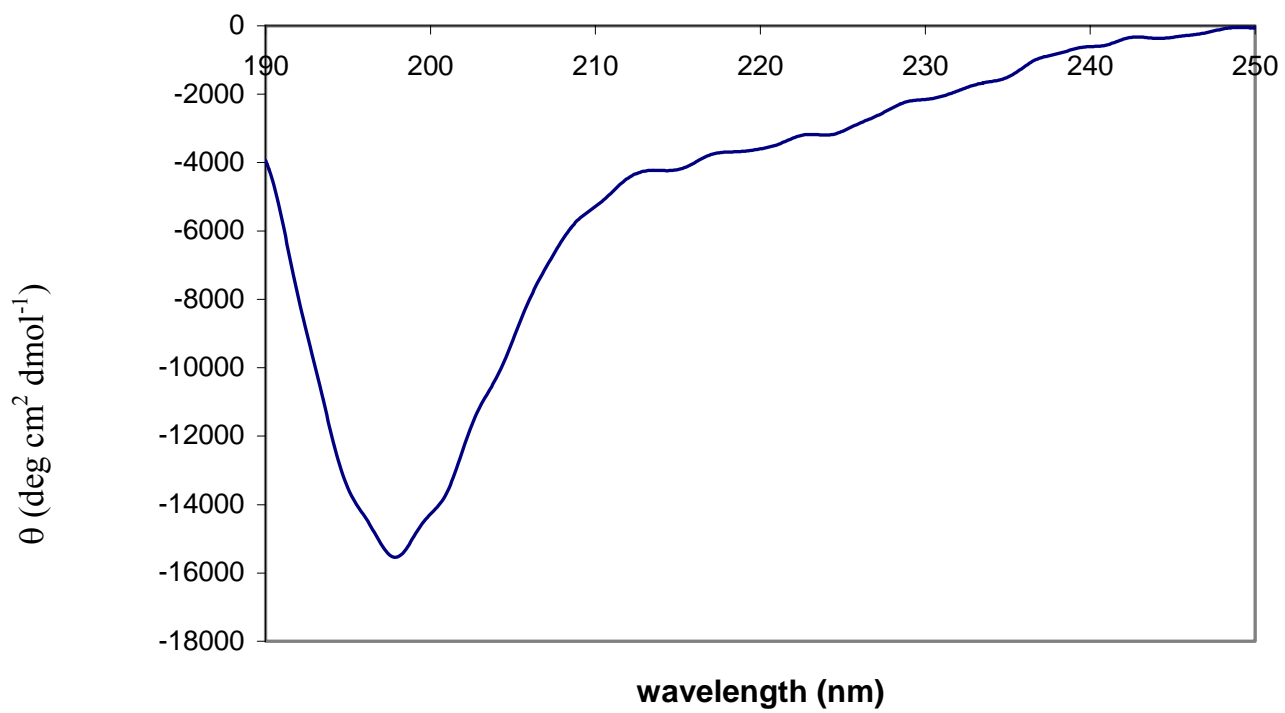

Figure S19. CD spectrum of peptide 6a $(300 \mu \mathrm{M})$ in aqueous $\mathrm{CD}_{3} \mathrm{CN}$ containing $\mathrm{NaHCO}_{3}$ buffer. 


\section{(e) 2D-NMR Studies of Peptide 6a}

All spectra were recorded on a Bruker AV 600 spectrometer. In a $1.0 \mathrm{~mL}$ eppendorf tube, $100 \mu \mathrm{L}$ of $6 \mathbf{a}$ $\left(1 \mathrm{mg} / \mathrm{mL}\right.$ in $\left.\mathrm{H}_{2} \mathrm{O}\right), 20 \mu \mathrm{L}$ of $\mathrm{NaHCO}_{3}\left(4 \mathrm{mg} / \mathrm{mL}\right.$ in $\left.\mathrm{H}_{2} \mathrm{O}, \mathrm{pH} 8.3\right)$ and $860 \mu \mathrm{L}$ of $\mathrm{CD}_{3} \mathrm{CN}_{2} \mathrm{H}_{2} \mathrm{O}(3: 2)$ were mixed. $600 \mu \mathrm{L}$ of the mixture was transferred to a NMR tube. 1D Proton spectra were recorded for the peptide mixture from 0 to $25^{\circ} \mathrm{C}$ in steps of $5{ }^{\circ} \mathrm{C}$. The homonuclear two-dimensional NOESY spectra were obtained at $5{ }^{\circ} \mathrm{C}$ at $350 \mathrm{~ms}$ mixing time using WATERGATE technique for water suppression [Piotto, M.; Saudek, V.; Sklenar, V. J. Biomol. NMR 1992, 2, 661]. The data were acquired with 20418 complex points in the direct dimension, and 256 data point in the indirect dimension. The States-TPPI method [Marion, D.; Wuthrich, K. Biochem. Biophys. Res. Commun. 1993, 113, 967] was used for quadrature detection in $\mathrm{t}$. The proton chemical shifts were referred to sodium salt of 3(trimethylsilyl)-propionate-2,2,3,3- $d_{4}$.

On the basis of the NOESY spectrum of $6 \mathbf{a}\left(\mathrm{H}_{2} \mathrm{~N}-\mathrm{YTSSSKNVVR}-\mathrm{CO}_{2} \mathrm{H}\right)$, an inter residue NOE signal was observed between $\mathrm{K} 6 \mathrm{NH}$ proton and Y1 phenyl ring proton, indicating that the distance between these protons was less than $5 \AA$.

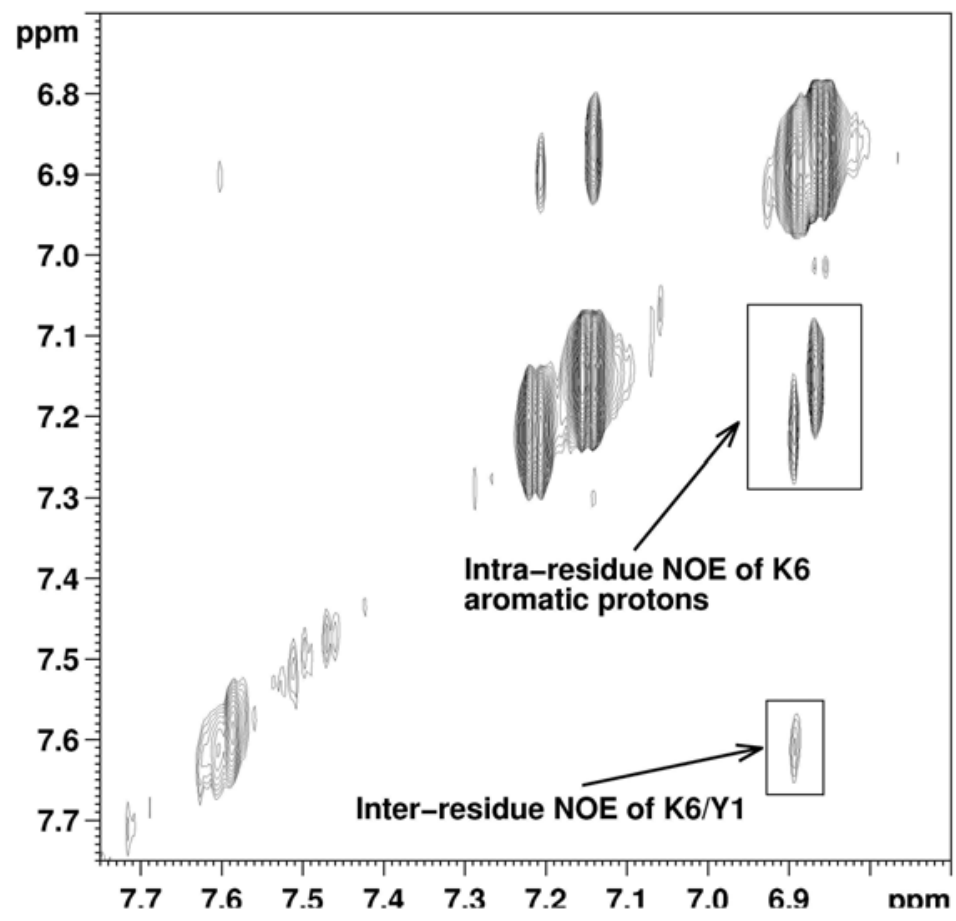

Figure S20. HN-H (aromatic) regions of the NOESY spectrum $(600 \mathrm{MHz})$ of peptide 6a $(100 \mu \mathrm{M})$ with key NOEs labeled. 